Universidade de São Paulo

Escola de Enfermagem

Rosemary Cristina Marques Simoni

Avaliação da Implantação da visita de Enfermagem com Familiares de pacientes de uma Unidade de Terapia Intensiva Adulto

São Paulo

2012 
Rosemary Cristina Marques Simoni

\title{
Avaliação da Implantação da visita de Enfermagem com Familiares de pacientes de uma Unidade de Terapia Intensiva Adulto
}

\author{
Dissertação apresentada ao \\ Programa de Pós-Graduação em \\ Enfermagem na Saúde do Adulto da \\ Escola de Enfermagem da Universidade \\ de São Paulo, para obtenção do \\ título de Mestre em Ciências.
}

Área de Concentração: Enfermagem na Saúde do Adulto

Orientadora: $\operatorname{Prof}^{\underline{a}}{ }^{-} r^{a}$ Maria Júlia Paes da Silva

São Paulo

2012 
AUTORIZO A REPRODUÇÃO E DIVULGAÇÃO TOTAL OU PARCIAL DESTE TRABALHO, POR QUALQUER MEIO CONVENCIONAL OU ELETRÔNICO, PARA FINS DE ESTUDO E PESQUISA, DESDE QUE CITADA A FONTE.

Assinatura:

Data:

\section{Catalogação na Publicação (CIP)}

Biblioteca "Wanda de Aguiar Horta"

Escola de Enfermagem da Universidade de São Paulo

Simoni, Rosemary Cristina Marques

Avaliação da implantação da visita de enfermagem

com familiares de pacientes de uma unidade de terapia

intensiva adulto / Rosemary Cristina Marques Simoni -

São Paulo, 2012.

$64 \mathrm{p}$.

Dissertação (Mestrado) - Escola de Enfermagem da Universidade de São Paulo.

Orientadora: Profa Dra Maria Júlia Paes da Silva

Área de concentração: Enfermagem na saúde do adulto

1. Comunicação 2. Família 3. Enfermagem em unidades de terapia intensiva 4. Equipe de enfermagem I. Título. 
Nome: Rosemary Cristina Marques Simoni

Título: Avaliação da Implantação da visita de Enfermagem com

Familiares de pacientes de uma Unidade de Terapia Intensiva Adulto

Dissertação apresentada ao

Programa de Pós-Graduação em

Enfermagem na Saúde do Adulto da

Escola de Enfermagem da Universidade de São Paulo, para obtenção do

título de Mestre em Ciências.

Aprovado em:

\section{Banca Examinadora}

Prof. Dr.

Instituição:

Julgamento:

Assinatura:

Prof. Dr.

Instituição:

Julgamento: Assinatura:

Prof. Dr.

Instituição:

Julgamento:

Assinatura: 


\section{Dedicatória}

Aos meus pais Alzira e Geraldo Marques que sempre me incentivaram nos estudos proporcionando os meios para que eu pudesse chegar até aqui.

Ao meu marido Francisco por compreender e apoiar minhas escolhas profissionais.

Ao meu filho Nicolas que é a melhor parte de mim. 


\section{Agradecimentos}

À Deus por permitir que eu tivesse uma gravidez tranquila me possibilitando dar continuidade ao trabalho.

À Professora Maria Júlia Paes da Silva por acreditar e investir em mim, me ensinando a trilhar pelos caminhos da pesquisa e também pela sua seriedade e compromisso com a orientação. 
Simoni RCM. Avaliação da Implantação da visita de Enfermagem com Familiares de pacientes em uma Unidade de Terapia Intensiva Adulto [Dissertação]. São Paulo: Escola de Enfermagem da USP; 2012.

\section{Resumo}

Estudo de abordagem quantitativa que tem como objetivo implantar a Visita de Enfermagem na UTI e verificar se as necessidades verbalizadas pelos familiares dos pacientes, durante a mesma e em estudos preliminares realizados no mesmo local, foram atendidas. Método: Após autorização do Comitê de Ética e Pesquisa do Hospital Universitário da USP foi implementada a Visita de Enfermagem na UTI adulto no período da manhã. Foi questionado aos familiares se gostariam de receber alguma informação por parte da Enfermagem e após ser dada as informações, foi questionado se ficou alguma dúvida. Após a alta do paciente da UTI, os familiares foram convidados a responder um questionário de avaliação do atendimento. Os que aceitaram participar assinaram o Termo de Consentimento Livre e Esclarecido. Após o questionário respondido, foram comparadas as respostas com as necessidades levantadas nos estudos preliminares e verificado se as mesmas foram suprimidas. Foi utilizada a estatística descritiva para avaliar a frequência, média e desvio-padrão das variáveis de interesse. As respostas obtidas com as questões abertas foram objetivas e apresentadas na forma de frequência e porcentagem de ocorrência de cada categoria. Resultado: Os familiares analisados eram na maioria do sexo feminino, com grau de parentesco "filha" seguido de "esposa", na faixa de 47 anos, dona de casa, com Ensino Médio completo. Todos os familiares quiseram receber informações do enfermeiro nas visitas realizadas tendo uma duração média de 8 minutos cada. Os temas de maior dúvida entre os familiares nas Visitas de Enfermagem foram o Estado Clínico do paciente e a Alta da UTI. Comparando as dúvidas levantadas nas visitas de Enfermagem verificamos que o número médio de dúvidas diminuiu da primeira para a última visita. $\mathrm{Na}$ análise do questionário, todos os familiares afirmam terem recebido as informações que gostariam de saber, não tendo ficado nenhuma dúvida em relação às informações que lhes foram transmitidas. O tempo de visita foi satisfatório para a maioria dos familiares entrevistados, assim como o atendimento durante o horário de visita; porém, alguns familiares ainda sentem necessidade de um maior tempo de contato com o doente e uma flexibilidade de rodízio de visita. Comparando o resultado deste estudo com o resultado do estudo realizado anteriormente no mesmo local, observou-se que houve um aumento no contato com a equipe de Enfermagem por meio da Visita de Enfermagem, porém, os familiares reafirmam a necessidade de um maior contato com o ente querido. Conclusão: Concluímos que a implementação da Visita de Enfermagem atendeu seu objetivo que foi atender as principais necessidades dos familiares durante o horário de visita respondendo suas questões sobre o cuidado de Enfermagem prestado para o paciente. Também foi observado que com a visita diária de Enfermagem as dúvidas e ansiedades dos familiares diminuíram no decorrer dos dias enfatizando a necessidade desse contato entre Enfermeiros e Familiares. Considera-se importante trabalhar com a equipe de Enfermagem estratégias de comunicação para que todos consigam atender as necessidades dos familiares durante a visita, visto que alguns Enfermeiros ainda sentem dificuldade nesta interação. 
Palavras Chaves: Comunicação, Unidade de Terapia Intensiva, Família, Enfermagem, Visita 
Simoni RCM. Evaluation of the Implantation of the Nursing visit in an ICU [thesis]. São Paulo (SP), Brasil: Escola de Enfermagem, Universidade de São Paulo; 2012.

\begin{abstract}
Study quantitative that has as objective to implant the Visit of Nursing in the ICU and to verify if the necessities spoken for the family ones of the patients, during the same one and in carried through preliminary studies in the same local, they had been taken care of. Method: After authorization of the Committee of Ethics and Research of the University Hospital of the USP was implemented the Visit of Nursing in the adult ICU in the period of the morning. It was questioned to the family ones if they would like to receive some information on the part from the Nursing and after to be given the information, was questioned if it was some doubt. After the high one of the patient of the ICU, the family ones had been invited to answer a questionnaire of evaluation of the attendance. The ones that they had accepted to participate had signed the Term of Free and Clarified Assent. After the answered questionnaire, had been compared the answers with the necessities raised in the preliminary studies and verified if the same ones they had been suppressed. The descriptive statistics was used to evaluate the frequency, average and shunting line-standard of the interest variable. The answers gotten with the open questions objective and had been presented in the form of frequency and percentage of occurrence of each category. Result: The family ones analyzed were in the majority of the female sex, with degree of kindred "followed son" of "wives", in the band of 47 years, house owners, with complete Average Education. All the familiar ones had wanted to receive information from the nurse in the three carried through visits having an average duration of 8 minutes each. The subjects of bigger doubt enter the familiar ones in the three Visits of Nursing had been the Clinical State of the patient and the High one of the ICU. Comparing the doubts raised in the three visits of Nursing we verify that the average number of doubts diminished of the first one for the third visit. In the analysis of the questionnaire, all the familiar ones affirm to have received the information that would like to know, not having been no doubt in relation to the information that had been transmitted to them. The visit time was satisfactory for the majority of the familiar ones interviewed, as well as the attendance during the visit schedule; however, some familiar ones still feel necessity of a bigger time of contact with the sick person and a flexibility of visit caster. Comparing the result of this study with the result of the study carried through previously in the same local, it was observed that it had an increase in the contact with the team of Nursing through the Visit of Nursing, however, the family ones reaffirm the necessity of a bigger contact with the dear being. Conclusion: We conclude that the implementation of the Visit of Nursing took care of its objective that was to take care of the main necessities of familiar during the visit schedule answering its questions on the care of Nursing given for the patient. Also it was observed that with the daily visit of Nursing the doubts and anxiety of the family ones had diminished in elapsing of the days having emphasized the necessity of this contact of Family Nurses. It is considered important to work with the team of Nursing communication strategies so that all obtain to take care of the necessities of the family ones during the visit, since some Nurses still feel difficulty in this interaction.
\end{abstract}


Keys Words: Comunication; ICU; Family; Nursing; Visit 


\section{Lista de llustrações}

Figura 1- Distribuição dos familiares por gênero.

Figura 2- Distribuição dos familiares por grau de parentesco.

32

Figura 3- Distribuição da profissão dos familiares.

Figura 4- Box Plot - Idade dos familiares.

Figura 5- Distribuição da escolaridade dos familiares por sexo. 


\section{Lista de Tabelas}

Tabela 1- Distribuição amostral - Idade x Sexo dos familiares.

Tabela 2- Número de famílias que apresentaram dúvidas sobre os temas no primeiro dia de Visita de Enfermagem.

Tabela 3- Número de famílias que apresentaram dúvidas sobre o item "outros" no primeiro dia de Visita de Enfermagem.

Tabela 4- Número de famílias que apresentaram dúvidas sobre os

temas no segundo dia de Visita de Enfermagem.

Tabela 5- Número de famílias que apresentaram dúvidas sobre o item "outros" no segundo dia de Visita de Enfermagem.

Tabela 6- Número de famílias que apresentaram dúvidas sobre os temas no terceiro dia de Visita de Enfermagem.

Tabela 7- Número de famílias que apresentaram dúvidas sobre

o item "outros" no terceiro dia de Visita de Enfermagem.

Tabela 8- Número de dúvidas para cada dia de visita.

Tabela 9- Teste t pareado comparando as dúvidas entre os dias de visita. 40

Tabela 10- Número médio de dúvidas entre os sexos por dia de visita. 


\section{Sumário}

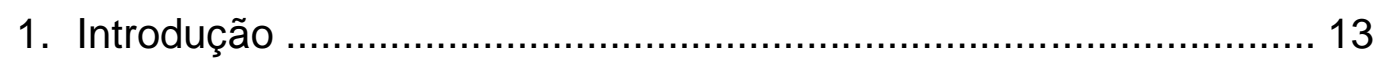

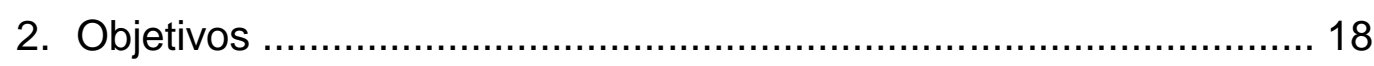

3. Referencial Teórico

3.1 Definição de família e visitante na UTI.................................. 19

3.2 Aspectos que influenciam a interação positiva entre equipe de saúde e família ................................................. 20

3.3 Aspectos que influenciam a interação negativa entre equipe de saúde e família ................................................. 24

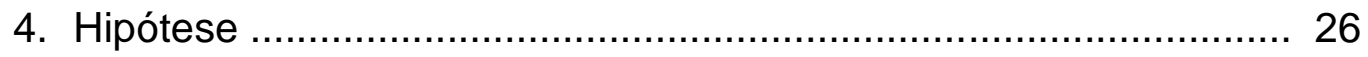

5. Método

5.1 Tipo de estudo ....................................................... 27

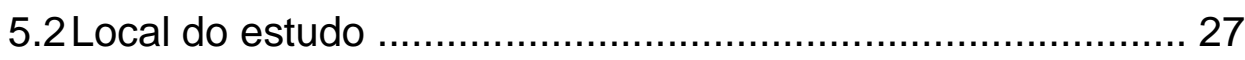

5.3 População................................................................. 28

5.4 Procedimentos de Coleta de dados................................ 28

5.5 Tratamento dos Dados ................................................. 30

6. Apresentação dos resultados

6.1 Caracterização dos pacientes ..................................... 31

6.2 Caracterização dos familiares ........................................ 31

6.3 Caracterização das Visitas de Enfermagem ........................ 35

6.4 Caracterização do questionário pós alta do paciente da UTI ............................................................... 41

7. Discussão dos Resultados ................................................ 43

8. Conclusões e Considerações Finais ........................................ 50

9. Limitações do Estudo ............................................................ 51

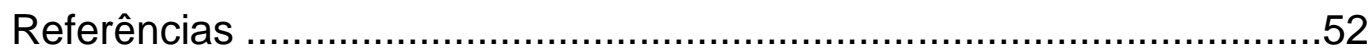

Apêndice

Apêndice I 


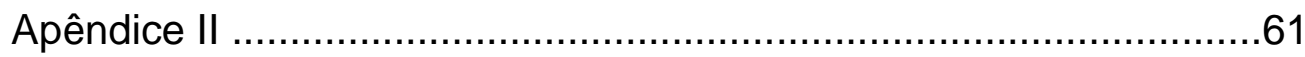

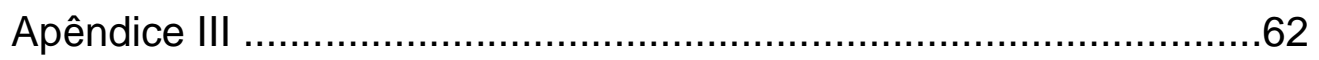

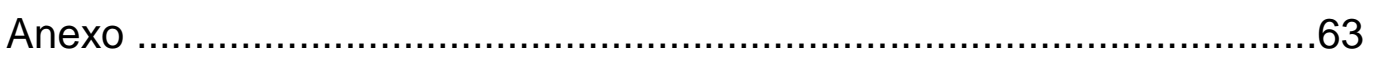




\section{INTRODUÇÃO}

A UTI é diferente de outras unidades de internação e, sobretudo, do ambiente de casa do paciente e seus familiares. É um ambiente que possui muitas máquinas, onde os indivíduos convivem em situações de emergências, risco e morte diariamente, onde há isolamento social e falta de privacidade. Compreendem os cuidados intensivos: a monitorização, cuidado integral, observação constante pela equipe de enfermagem e plantão médico contínuo, a disposição de recursos de emergências e de equipe técnica capacitada para atender às necessidades desses pacientes ${ }^{1}$.

O tratamento implantado neste ambiente é considerado agressivo e invasivo, traduzindo-se por uma alta intensidade e complexidade de eventos e situações ${ }^{2}$. Pode ser menos hostil ao paciente e sua família se os profissionais de saúde humanizarem a assistência, ou seja, perceberem cada ser humano como um indivíduo único, com necessidades específicas, otimizando o exercício de sua autonomia, facilitando a interação entre eles por meio de diálogo aberto entre quem cuida e quem é cuidado ${ }^{3}$.

A comunicação satisfatória entre 0 paciente e a equipe multiprofissional que o cerca é uma preocupação constante e importante na humanização da assistência. A habilidade de comunicar-se com o outro é uma das qualidades importantes para o enfermeiro, que deve demonstrar sensibilidade à comunicação não verbal e ter capacidade de ouvir atentamente, sabendo o que falar e quando falar, em linguagem clara e acessível ${ }^{4}$.

Se aceita que a qualidade e quantidade de assistência prestada ao paciente dependem, em grande parte, da influência dos processos de comunicação usados no setor de trabalho ${ }^{5}$.

Comunicação é o processo de compreender, compartilhar mensagens enviadas e recebidas, as próprias mensagens e o modo como ocorre seu 
intercâmbio, exercendo influência no comportamento das pessoas nele envolvidas, a curto, médio ou longo prazo; esta mudança pode ocorrer no ambiente em que a comunicação é efetuada ou quando as pessoas encontram-se isoladas, distantes umas das outras ou do contexto ${ }^{6}$.

Para que essas informações possam ser devidamente transmitidas, 0 enfermeiro deve lembrar-se que a comunicação envolve a linguagem verbal e não verbal, ou seja, que essa se processa além das palavras, por meio de gestos, expressões faciais, movimentos do corpo, distâncias mantidas entre as pessoas, por exemplo ${ }^{7}$.

Os enfermeiros necessitam criar estratégias de comunicação para atender as necessidades de pacientes que, geralmente, têm sua comunicação prejudicada por problemas físicos ou patológicos; familiares estressados com a súbita e inesperada internação de um ente conhecido; da própria equipe de saúde que pode ter alguns profissionais cansados vivenciando situações de urgência, autoridade de diversos membros e barreiras na comunicação entre os serviços de apoio ${ }^{8}$.

O contato familiar permite a construção da formação moral, crenças, sentimentos e conhecimento; por isso, se a enfermeira consegue obter um relacionamento satisfatório com o familiar do cliente, obtém informações enriquecedoras, podendo assim oferecer um cuidado a partir de suas necessidades ${ }^{9}$.

Ressalta-se que o entendimento das necessidades de clientes debilitados tem um significado não somente para os clientes, mas também para seus familiares ${ }^{9}$. Assim, o cliente internado em UTI necessita de cuidados de excelência, dirigidos não apenas para os problemas fisiopatológicos, mas também para as questões psicossociais, ambientais e familiares que se tornam intimamente interligadas à doença física ${ }^{10}$.

Há uma percepção dos pacientes, mesmo os muito dependentes de cuidados técnicos, de que necessitam de pessoas para ampará-los em um momento de extrema fragilidade, causada pela incerteza da vida e pela total dependência do cuidado do outro. Esta percepção se estende aos 
acompanhantes/familiares que também possuem necessidades e experimentam conflitos relacionados à questão da tecnologia e da humanização do cuidado ${ }^{11}$. Neste contexto, é importante a presença do familiar; porém, é necessário aplicar o perfil educativo da enfermeira na condução do preparo do familiar no sentido de introduzi-lo a esse cenário complexo. O familiar presente na unidade e participante do cuidado ao cliente pode colaborar na compreensão de expressões de comunicação prejudicadas pelas restrições de comunicação verbal e corporal e participar do cuidado ${ }^{12-13}$.

As necessidades de familiares são caracterizadas por situações ou eventos de caráter físico e emocional, que podem ser vivenciadas por estarem com os entes queridos com uma doença grave e inesperada, internados na UTI. Essas necessidades podem ser exemplificadas por situações ou eventos como: saber quem pode dar informação sobre 0 familiar, sentir que há esperança de melhora, saber qual tratamento médico está sendo dado e ter orientações gerais sobre a UTI, na primeira visita ${ }^{14}$.

O primeiro estudo que se propôs a identificar as necessidades dos familiares de pacientes internados na UTI desenvolveu um instrumento com 45 necessidades, denominado Critical Care Family Need Inventory $(\mathrm{CCFNI})^{14}$.

No Brasil, o CCFNI foi adaptado e validado para a cultura brasileira, constituído por uma lista de 43 necessidades, denominado Inventário de Necessidades e Estressores de Familiares de Pacientes Internados em Terapia Intensiva (INEFTI) ${ }^{15}$.

Estudo realizado por Morgon e Guirardello ${ }^{16}$ que teve como objetivo validar a escala de necessidades de familiares de UTI, baseado no estudo de Castro $^{15}$, utilizando os métodos psicofísicos de estimação de magnitude (EM) e emparelhamento de comprimento de linhas (ECL), concluiu que as necessidades julgadas com maior grau de importância pelos familiares foram: sentir que o pessoal do hospital (UTI) se interessa pelo paciente; estar seguro de que o melhor tratamento possível está sendo dado ao paciente; sentir que há esperança de melhora; saber qual tratamento médico está sendo dado e ter perguntas respondidas com franqueza. A frequência 
das diferentes necessidades foi similar em ambos os métodos psicofísicos de EM e ECL.

Esses resultados foram similares ao do estudo de Marques, Silva e Maia $^{17}$ que avaliou a comunicação entre profissional de saúde e familiar de paciente internado em uma UTI e evidenciou a necessidade dos familiares de maior atenção por parte da equipe de enfermagem, que é a que fica mais próxima do paciente; a necessidade de um maior tempo de contato com o doente e uma maior flexibilidade de horários de visita; além de ter um espaço e disponibilidade de compartilhamento de sentimentos a respeito da situação em que a família se encontra, principalmente no momento de receberem más notícias.

Outro estudo realizado por Marques, Silva e Maia ${ }^{18}$ questionando entre os profissionais de saúde, que trabalham na UTI, o que seria uma comunicação efetiva entre equipe e familiar, e se os mesmos a praticam como profissionais evidenciou que os profissionais, na posição de familiares, gostariam de ter clareza da linguagem verbalizada, periodicidade nos contatos com a equipe e objetividade nas informações dadas pela equipe médica e de enfermagem; além da recepção pela equipe durante o horário de visita. Consideram importante receber informações, principalmente da Equipe de Enfermagem, que é a que permanece mais tempo ao lado do paciente.

Por trabalhar em uma Unidade de Terapia Intensiva Adulto e vivenciar no meu cotidiano as necessidades que as famílias apresentam durante 0 horário de visita com suas dúvidas, medos e incertezas e o não preparo adequado que a equipe de enfermagem possui no atendimento dessas famílias, baseado nos resultados dos estudos citados ${ }^{17-18}$, sentiu-se a necessidade de criar estratégias para melhorar o atendimento dos familiares durante o horário de visita visando proporcionar melhora na qualidade do atendimento de enfermagem prestado. Para isso, foi proposto implementar a visita de Enfermagem, e avaliar se a mesma é efetiva para melhorar o atendimento dos familiares e suprir suas necessidades. Neste contexto, 
avaliar significa realizar a apreciação valorativa de uma determinada intervenção, trata-se, tal como nas ciências sociais, "...de uma forma de valoração sistemática que se baseia no emprego de procedimentos que, apoiados no uso do método cientifico, servem para obter e proporcionar a informação pertinente e julgar o mérito e o valor de algo, de maneira justificável’19.

O termo Visita de Enfermagem foi criado pela autora para nomear uma forma de comunicação estruturada com a família de pacientes de UTI, o que vem sendo comprovado por pesquisas recentes 20 -21-22-23-24-25-26, que aumenta a satisfação da família e atende as necessidades da mesma quando estão vivenciando uma internação de um ente querido na UTI. 


\section{OBJETIVOS}

Diante da problemática exposta, temos como objetivos neste trabalho:

- Implementar a visita de Enfermagem na UTI;

- Verificar e atender as principais necessidades de informação e acolhimento verbalizadas pelas famílias durante as visitas de Enfermagem;

- Aplicar um questionário de avaliação de atendimento para os familiares, após a alta do paciente da UTI, e comparar se as necessidades levantadas no primeiro momento foram suprimidas pela visita de enfermagem;

- Comparar o resultado da avaliação das necessidades expressas com os resultados dos estudos realizados anteriormente no mesmo local. 


\section{REFERENCIAL TEÓRICO}

Os estudos que investigaram vários aspectos da interação humana dentro do cuidado crítico foram dividido em 3 temas principais: definição de família e visitante na UTI, aspectos que influenciam na interação positiva entre equipe de saúde e família e aspectos que influenciam na interação negativa entre equipe de saúde e família na UTI.

\subsection{DEFINIÇÃO DE FAMÍLIA E VISITANTE NA UTI}

O conceito de família vem sofrido muitas transformações no decorrer dos anos. Hoje em dia a composição familiar não se restringe apenas ao pai, mãe e filhos, mas também são considerados os avós, tios e primos e a união homossexual, ou seja, todos os que fazem parte do circulo afetivo do paciente tendo como melhor definição: "a família é quem seus membros dizem que são"16,27-28-29-30.

O modelo proposto por Allmond, Buckman e Gofman ${ }^{31}$, define a família como se fosse um móbile e cada membro é representado por uma peça do brinquedo. A soma das peças forma o todo e, por sua vez, todas elas, por mais diferentes que sejam, são feitas para ocuparem um lugar cujo resultado comum é o equilíbrio. A doença e a morte trabalham como eventos que desequilibram o sistema familiar, assim como se alguém removesse uma peça do móbile ${ }^{30}$.

Na perspectiva interacionista, família pode ser definida como "um grupo de indivíduos em interação simbólica, chegando às situações com os outros significantes ou grupos de referência, com símbolos, perspectivas, self, mente e habilidade para assumir papéis"32. 


\subsection{ASPECTOS QUE INFLUENCIAM A INTERAÇÃO POSITIVA ENTRE EQUIPE DE SAÚDE E FAMÍLIA.}

Partindo do princípio que a informação é reconhecida como um direito do cliente e dever do profissional, uma boa anamnese da família é imprescindível para conhecer sua vida pregressa, sua situação atual, suas forças, fraquezas, estrutura familiar e a rede de apoio acessada durante a experiência de hospitalização de um familiar. Os aspectos importantes na comunicação com famílias nessa unidade são: fornecer informações claras, concisas e com linguagem apropriada; permitir que os familiares perguntem e digam o que pensam e sentem, bem como, incentivá-los a falar sobre a situação que se encontram; transmitir as informações com sensibilidade e no momento oportuno, pois, quando transmitidas em momentos iniciais do processo da hospitalização, às vezes podem ser mal interpretadas ou não decodificadas pelos familiares. Realizando uma comunicação adequada, a interação da família com a Enfermagem tende a ser harmônica, manifestando comportamento mais tranqüilo e colaborativo, além de propiciar um cuidado humanizado ${ }^{13,17,33-34-35-36}$.

Um estudo realizado em 90 UTIs da França, com 951 familiares de pacientes, demonstrou que houve um aumento no tempo de contato da equipe médica da UTI com os familiares em situações de: piora do quadro clínico, admissão na UTI ou quando o paciente estava intubado. Porém, o estudo mostrou que somente aumentar o tempo de contato com o familiar não significa, necessariamente, aumento da satisfação desse familiar. O que realmente importa é a qualidade, ou seja, habilidade em dar a informação, com que esse contato é feito ${ }^{37}$.

Estudo realizado em 4 hospitais de Seattle verificou se há relação entre a habilidade de comunicação do médico com a satisfação da família durante o horário de visita. Foi verificado que as famílias relatam a maior satisfação quando os médicos asseguram à família que seu familiar não será abandonado mesmo estando para morrer; que o paciente está confortável e 
não sofrerá, e assegura a continuidade do cuidado até o final da vida. A coerência da expressão verbal e da expressão não verbal ao trocar informações e a não contradição de informações também podem influenciar na satisfação da família ${ }^{38}$.

Ao transmitir uma má notícia sobre o paciente para o familiar, 0 profissional de saúde deve estar atento aos aspectos emocionais desse familiar, pois a carga emocional pode dificultar a compreensão da mensagem. Uma possível intervenção para essa dificuldade seria 0 profissional clarificar e validar as mensagens que transmite às famílias, com o objetivo de explicar aquilo que está sendo dito e verificar a existência de significações comuns para ambos ${ }^{33}$.

O estudo realizado por Pinheiro et $\mathrm{al}^{33}$, mostrou que a família, diante da internação da criança, mostrou-se com ou sem esperança, com forças ou fraquezas, com segurança ou insegurança, dependendo da forma como a má notícia foi transmitida pelo profissional de saúde.

Os familiares de pacientes em cuidados paliativos na UTI possuem necessidades específicas de cuidado e atenção, pois as consequências de uma comunicação inadequada, como ansiedade, depressão e dificuldade na tomada de decisão, podem ocorrer não somente em curto prazo, mas também a longo prazo ${ }^{39}$. Esse resultado foi verificado no estudo de Boyle, Miller e Forbes-Thompson ${ }^{40}$ que concluiu que as equipes médicas e de enfermagem das UTIs necessitam de habilidades de comunicação para melhorar a interação com a família de pacientes em cuidados paliativos, podendo usar estratégias como: reuniões formais e informais com a família e consenso nas informações por todos da equipe. $O$ estudo de Levin et $\mathrm{al}^{41}$ também chegou a conclusões semelhantes quando afirmam que a equipe de saúde da UTI necessita adquirir habilidades para se comunicar com familiares de pacientes em cuidados paliativos, afim de minimizar o impacto da morte na família. 
Estudos mostram que os aspectos que facilitam a comunicação do familiar com o profissional são seu interesse para se aproximar da família, sua empatia por ela, a idade avançada do familiar que estimula a aproximação do profissional, seu tempo de experiência na área e sua reflexão sobre o autoconhecimento possibilitando a instrumentalização para estabelecer uma comunicação mais afetiva e menos mecânica com as famílias atendidas ${ }^{18,35,42-43}$.

Outros estudos relacionam como necessidades dos familiares, a ênfase no fornecimento de informação, o desejo que o paciente seja bem tratado, a necessidade de acolhimento, de atenção e de afeto ${ }^{28,34}$.

O uso de folhetos informativos sobre o processo de cuidado, a definição de alguns termos técnicos e de intervenções, assim como a estruturação física e organizacional da UTI podem auxiliar no processo de comunicação entre a equipe e a família ${ }^{29}$. Assim como também demonstrado em estudos recentes sobre comunicação estruturada com a família de pacientes de UTI que têm demonstrando a eficácia de intervenções para melhorar a comunicação e a tomada de decisão em unidades criticas, como encontros formais e multiprofissionais com a família e uso de folhetos informativos sobre a UTI 20-21-22-23-24.

É observado que a permanência de familiares é mais aceita em UTIs pediátricas e neonatais, sendo encontradas maiores dificuldades nas UTIs de adulto e Idoso. Porém, o relacionamento terapêutico da enfermeira com o paciente pode ser facilitado com a presença da família na UTI, pois a maioria dos pacientes apresenta comunicação prejudicada por barreiras físicas ou psicológicas $^{29}$. A família pode ajudar a enfermagem a cuidar do paciente e dar informações sobre ele, à equipe de saúde, e também proporcionar bem estar, felicidade e informações facilitadoras à assistência, como valores, crenças e gostos, hábitos e expressões comuns, favorecendo um relacionamento terapêutico com o paciente ${ }^{11,13,28,34,44}$.

As enfermeiras reconhecem a importância da presença da família como participante do cuidado, mas nem sempre conseguem inseri-las neste, 
pois, para isso, devem ser capazes de reconhecer as necessidades dos familiares e possibilitar seu papel no cuidado, promovendo uma comunicação que possibilite uma relação simétrica, flexível e colaborativa entre família e profissional ${ }^{13,33-34,37}$.

Um estudo realizado em uma UTI de um hospital no Reino Unido mostrou que o papel da família não é só obter informações sobre o paciente, mas também oferecer um suporte emocional vital para o paciente diminuindo sua ansiedade. Os membros da família têm a vantagem de saber o que é de interesse dos pacientes podendo fornecer-lhes essas informações, o que pode introduzir alguma normalidade no dia a dia do paciente, propiciandoIhes alguma distração ou diversão. As enfermeiras, neste estudo, identificaram que os membros da família podem precisar de apoio em dois itens principais para manter uma interação terapêutica com seu parente na UTI: simplificação de uma comunicação verbal com paciente intubado ou sedado, cuja intervenção foi orientar a família a fazer perguntas que pudessem ser respondidas com sim e não; e a permissão para tocar no paciente e ajudar no cuidado, o que foi incentivado pelas enfermeiras ${ }^{46}$.

É preciso quantificar e adequar os funcionários para atender 0 impacto da atenção à família dentro da UTI preparando e sensibilizando-os para que ofereçam condições adequadas de estrutura física, de atendimento psicológico, emocional e de informação ${ }^{11}$. Com essas intervenções, também haverá uma melhora da comunicação entre todos os membros da equipe, como foi demonstrado no estudo de Shelton et $\mathrm{al}^{47}$.

Estudo realizado por Kentish-Barnes et $\mathrm{al}^{48}$ concluiu que se a carga emocional da família for mensurada durante todo o período de internação de um parente, e for corretamente trabalhada pela equipe de saúde com uma comunicação eficaz, pode-se detectar e prevenir precocemente sintomas de ansiedade, depressão e estresse vivenciados pelos familiares. 


\subsection{ASPECTOS QUE INFLUENCIAM A INTERAÇÃO NEGATIVA ENTRE EQUIPE DE SAÚDE E FAMÍLIA.}

A UTI ainda está associada ao fim da vida e não à recuperação da saúde para muitas pessoas. Os familiares sentem-se frequentemente intimidados e com medo da morte demonstrando desespero, angústia e fragilidade ao se deparar com este quadro delicado do ente querido ${ }^{28,34,49}$.

Na maioria dos casos, a família está entrando nesse local e passando por esta situação de ter um de seus membros hospitalizados pela primeira vez, portanto tudo é novidade para eles e precisam enfrentar essa situação desconhecida, com a qual não contavam ${ }^{34}$.

Assim, os familiares chegam na unidade intensiva com medo do estado do paciente e da cena que irão ver. Apresentam-se perdidos porque não conhecem os rituais desse setor e permanecem muito aflitos para falar com alguém da equipe, a fim de obter informação sobre o paciente, esclarecer dúvidas, assim como ter satisfeita sua necessidade de conforto, receber palavras carinhosas e de atenção ${ }^{34,45,49}$.

A equipe, muitas vezes, não está preparada para informar os familiares de que irão encontrar seus entes abatidos, muitas vezes edemaciados, portando aparelhos, fios, sondas e drenos ${ }^{34}$.

Poucas são as UTI que dispõem de boxes individualizados, locais reservados para a comunicação com familiares e políticas de flexibilização do acesso ou mesmo de acesso livre aos familiares de pacientes, mesmo aqueles em situação de terminalidade. A flexibilização das políticas de visitação e a autorização da entrada de mais familiares ao mesmo tempo é desejável. Para aqueles que experimentam a perda de um ente querido, este esforço organizacional pode representar muito. Há necessidade de alguém da equipe de Enfermagem ser referência para os familiares; alguém a quem 
eles possam recorrer para uma conversa, esclarecimento de suas dúvidas e ser tranqüilizados e orientados ${ }^{29,50}$.

Estudos mostram que a conversa com a família durante o horário de visita é tida como o momento mais difícil e cansativo da UTI para os profissionais de saúde. A transferência da responsabilidade da informação para outro profissional, o fornecimento de pouca ou nenhuma informação, as sensações de medo e sentir-se "encurralado" foram sentimentos e comportamentos manifestos pelos profissionais de saúde. As dificuldades nessa comunicação foram: informações nem sempre compreendidas pelos familiares, a gravidade do paciente, a própria dinâmica da unidade, o grau de desconhecimento pelo profissional de saúde da evolução clínica do paciente, além do desconhecimento do modo de ser e perceber da família; dificuldades que são inerentes ao próprio jeito de ser do profissional e espaço físico inadequado da unidade ${ }^{18,42}$.

A família, durante a visita na UTI, percebe que a equipe de saúde mostra atitudes de distanciamento, indiferença e desvalorização de seu sofrimento, ocasionando momentos de incerteza, o que pode reduzir a capacidade da família de enfrentar a situação de maneira menos traumática ${ }^{33,43}$.

O grau de escolaridade do familiar também serve como barreira de comunicação entre o visitante e a equipe de saúde, pois muitos referem se sentir inibidos e até temerosos em fazer perguntas e expor suas necessidades e angústias ${ }^{49}$.

Estudos realizados comprovam que as queixas mais freqüentes que geraram maior incomodo na internação na UTI, referiram-se a médicos diferentes fornecendo as informações sobre o paciente, ausência de um local próprio para conversar sobre o paciente, falta de pontualidade do início do horário de visita e percepção de contradições nas informações recebidas $^{29,50-51}$. 


\section{HIPÓTESE DO ESTUDO}

A partir de uma interação efetiva, com a visita de enfermagem, é possível atender as necessidades de informação e acolhimento verbalizadas pelos familiares. 


\section{MÉTODO}

\subsection{TIPO DE ESTUDO}

Estudo de abordagem quantitativa descritiva e de Campo.

As pesquisas quantitativas têm como objetivo mensurar e permitir o teste de hipóteses, já que os resultados são concretos. Em muitos casos cria-se índices que podem ser comparados ao longo do tempo, permitindo traçar um histórico de informação. Mostra-se apropriada quando existe a possibilidade de medidas quantificáveis de variáveis e inferências a partir de amostras numéricas, ou busca padrões numéricos relacionados a conceitos cotidianos $^{52}$.

\subsection{LOCAL DO ESTUDO}

O estudo foi realizado na Unidade de Terapia Intensiva Adulto do Hospital Universitário da Universidade de São Paulo.

Esta UTI atende até 12 pacientes em estado crítico ou potencialmente crítico, de ambos os sexos, de todas as idades, a partir dos 15 anos, clínicos ou cirúrgicos e com qualquer tipo de patologia, caracterizando assim uma UTI geral.

A planta física desta UTI está dividida em 2 partes, sendo a primeira composta por 5 divisões com dois leitos cada uma, sendo que os leitos ficam um de frente para o outro sendo divididos por uma cortina totalizando 10 leitos numerados. A segunda parte fica do outro lado da UTI e é composta por 4 quartos de isolamento separados, um do lado do outro, por paredes divisórias e janelas de vidro. No centro da UTI ficam os balcões onde são 
guardados os materiais de uso na assistência e a mesa com os computadores. A UTI possui 3 postos de enfermagem, sendo dois localizados na primeira parte e um localizado ao lado dos isolamentos.

A visita é realizada em três horários: manhã (11:00 às 12:00h), tarde (16:00 às 17:00h) e noite (20:00 às 21:00h), sendo que o médico passa as informações para a família sobre o estado clínico do paciente no horário da tarde.

\subsection{POPULAÇÃO}

Foram entrevistadas 120 famílias de pacientes internados na Unidade de Terapia Intensiva do Hospital Universitário da USP no período de setembro de 2011 a janeiro de 2012. Deste total, vinte pacientes foram a óbito, sendo excluídos, juntamente com seus familiares, do estudo, compondo, então, 90 sujeitos de pesquisa (núcleos familiares desses pacientes internados).

Critérios de Inclusão: Familiares de pacientes com período de internação a partir de 24 horas, a partir do inicio da coleta de dados.

Critérios de Exclusão: Familiares de pacientes que foram a óbito durante 0 período de internação na UTI; Familiares de pacientes que permaneceram menos de 24 horas internados na UTI.

\subsection{PROCEDIMENTOS DE COLETA DE DADOS}

Após autorização do Comitê de Ética e Pesquisa da EEUSP e do HU (Registro CEP-HU/USP: 1123/11) foi implementada, pela pesquisadora, a visita de Enfermagem para os familiares de pacientes na UTI, que foi realizada uma vez por dia no período da manhã, por um período de 4 
meses. Nesta etapa foram avaliadas as principais necessidades verbalizadas por cada família.

Para esta primeira etapa, a pesquisadora convidou outros enfermeiros da unidade para também realizar as visitas de Enfermagem com os familiares e, para isso, foram utilizados dois formulários: sendo um da primeira visita, com 24 horas de internação do paciente (Apêndice I), e outro de acompanhamento diário até, no máximo, 3 visitas com o mesmo familiar (Apêndice II), para que todos seguissem o mesmo padrão, e os dados pudessem ser comparados posteriormente.

O protocolo para realização da Visita de Enfermagem utilizado por todos os enfermeiros está exposto a seguir.

Protocolo para realização da visita de enfermagem:

- Registrar o dia, a hora de início e término da visita de enfermagem;

- Registrar o nome do entrevistador, o paciente e o leito a ser realizado a visita de Enfermagem; o dia de internação do paciente e se há ou não presença de familiar;

- Apresentar-se para o familiar;

- Perguntar grau de parentesco e nome;

- Perguntar se o familiar gostaria de receber alguma informação por parte da Enfermagem e anotar que tipo de informação foi solicitada;

- Após serem dadas as informações, questionar e anotar se ficou alguma dúvida ou se gostariam de receber mais alguma informação.

Após a alta do paciente da UTI para as enfermarias, para melhor fidedignidade dos dados, os familiares foram convidados a responder um questionário de avaliação do atendimento (Apêndice III), em até 24 horas pós alta. Os que aceitaram participar assinaram o Termo de Consentimento Livre e Esclarecido (Anexo I). 
Visando preservar a autonomia do familiar em querer participar ou não do estudo, optou-se por não entregar para o familiar o Termo de Consentimento Livre e Esclarecido antes da realização da visita de Enfermagem, pois neste momento o paciente ainda estava na UTI recebendo os cuidados dos enfermeiros que estavam coletando os dados. Outro aspecto é que a visita de Enfermagem não prejudicou ou lesionou a integridade tanto do familiar como do paciente. Foi expresso no TCLE que os dados coletados durante a visita de Enfermagem seriam utilizados no trabalho de dissertação e para apresentação em eventos.

\subsection{TRATAMENTO DOS DADOS}

Após o questionário respondido, foram comparadas as respostas com as necessidades levantadas nos estudos preliminares referidas e as verbalizadas pela família e verificado se as mesmas foram suprimidas.

Toda análise estatística foi realizada no SPSS 17.0 e Minitab 14. Os gráficos foram gerados no Minitab Realese 14 ou no Excel 2010.

Foi utilizada a estatística descritiva para avaliar a frequência, média e desvio-padrão das variáveis de interesse. Os dados quantitativos foram apresentados na forma de média \pm desvio-padrão. As respostas obtidas com as questões abertas foram objetivas e apresentados na forma de frequência e porcentagem de ocorrência de cada categoria.

Para a comparação do número médio de dúvidas entre os dias de visitas, foi utilizado a ANOVA de medidas repetidas e para nível de comparação entre as datas foi utilizado o teste t pareado.

O nível de significância considerado foi de 5\%, ou seja, valores $p$ superiores a 0,05 foram considerados não significativos. 


\section{APRESENTAÇÃO DOS RESULTADOS}

\subsection{CARACTERIZAÇÃO DOS PACIENTES}

Foram abordadas, na visita de enfermagem, um total de 120 famílias de pacientes internados na Unidade de Terapia Intensiva do Hospital Universitário da USP no período de setembro de 2011 a janeiro de 2012. Deste total, vinte pacientes foram a óbito, sendo excluídos, juntamente com seus familiares, do estudo, conforme explicado anteriormente. Os outros noventa $(100 \%)$ foram categorizados da seguinte forma: quarenta e oito $(53,3 \%)$ são do sexo masculino e quarenta e dois $(46,7 \%)$ são do sexo feminino. Cinqüenta e um (56,7\%) foram internados por patologias clinicas e os outros trinta e nove $(43,3 \%)$ foram internados por patologias cirúrgicas. Em relação à idade houve uma média de 57,58 anos. Em relação ao tempo de internação houve uma média de 5,5 dias.

\subsection{CARACTERIZAÇÃO DOS FAMILIARES}

A figura 1 apresenta o número de familiares que fizeram parte do estudo $N=90(100 \%)$, sendo que mais da metade dos familiares $N=62$ $(68,9 \%)$ que realizaram as visitas aos internados são do sexo feminino. 


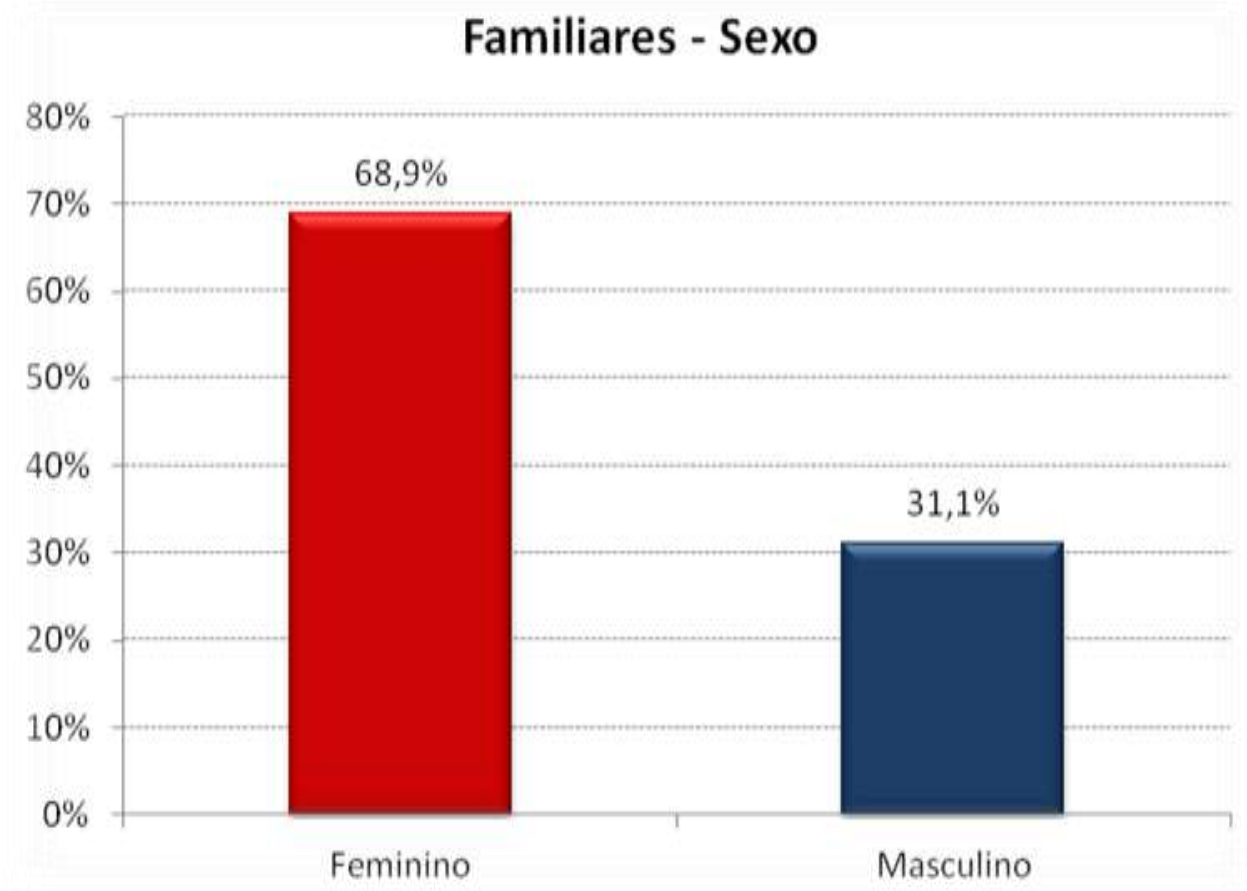

Figura 1- Distribuição dos familiares por gênero. São Paulo, 2011.

A figura 2 apresenta a distribuição do grau de parentesco com os internados: filhos $\mathrm{N}=35(38,9 \%)$ e cônjuge $\mathrm{N}=28(31,1 \%)$ são os que mais aparecem nas visitas.

\section{Grau de Parentesco}

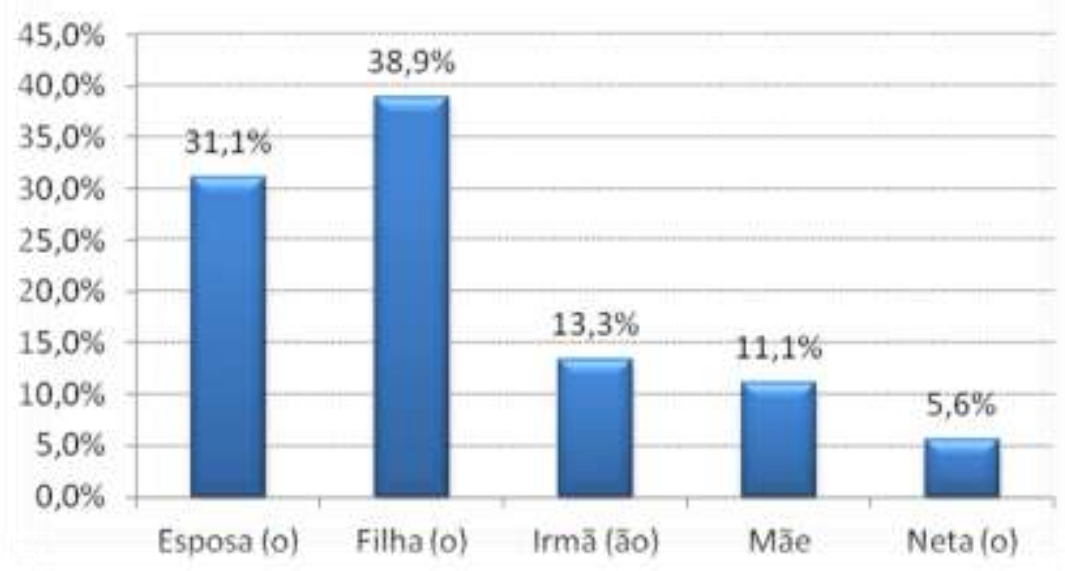

Figura 2- Distribuição dos familiares por grau de parentesco. São Paulo, 2011. 
A figura 3 apresenta a distribuição das profissões dos visitantes que fazem parte desse estudo. A maioria dos visitantes é "do lar" $N=29$ (32,2\%).

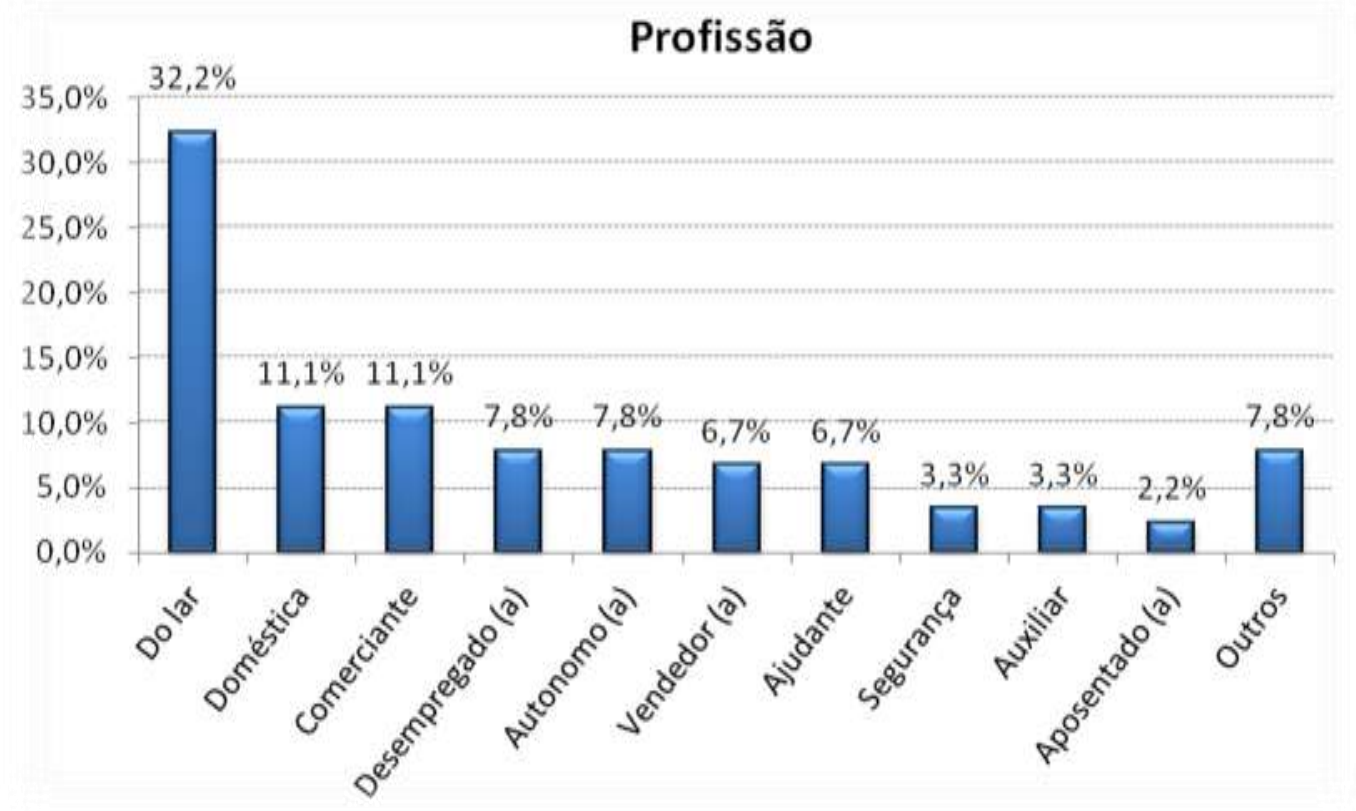

Figura 3- Distribuição da profissão dos familiares. São Paulo, 2011.

A tabela 1 apresenta a estatística descritiva da idade dos familiares que fizeram parte da análise. A idade média dos familiares (geral) é de 47 anos e desvio padrão $\pm 13,8$.

A mediana é de 47 anos, um valor bem próximo da média, indicando que a idade tem uma distribuição simétrica, ou seja, considerando os 90 familiares do estudo, 50\% deles tem acima de 47 anos e, consequentemente, os outros $50 \%$ tem abaixo de 47 anos.

O familiar mais novo que se apresentou para a visita tem 20 anos e o mais velho 79 , ambos do sexo masculino. 
Tabela 1- Distribuição amostral - Idade x Sexo dos familiares. São Paulo - 2011

\begin{tabular}{cccc}
\hline & Feminino & Masculino & Total \\
\hline Média \pm D.P. & $48 \pm 13.9$ & $46 \pm 13.8$ & $47 \pm 13.8$ \\
Mediana & 49 & 44 & 47 \\
Mínimo - Máximo & $23-74$ & $20-79$ & $20-79$ \\
\hline Total & 62 & 28 & 28 \\
\hline
\end{tabular}

A figura 4 apresenta o gráfico box plot, onde pode-se visualizar a distribuição da idade entre os visitantes do sexo feminino e sexo masculino. A linha do meio da caixa identifica a idade mediana e o ponto dentro da caixa é a média.

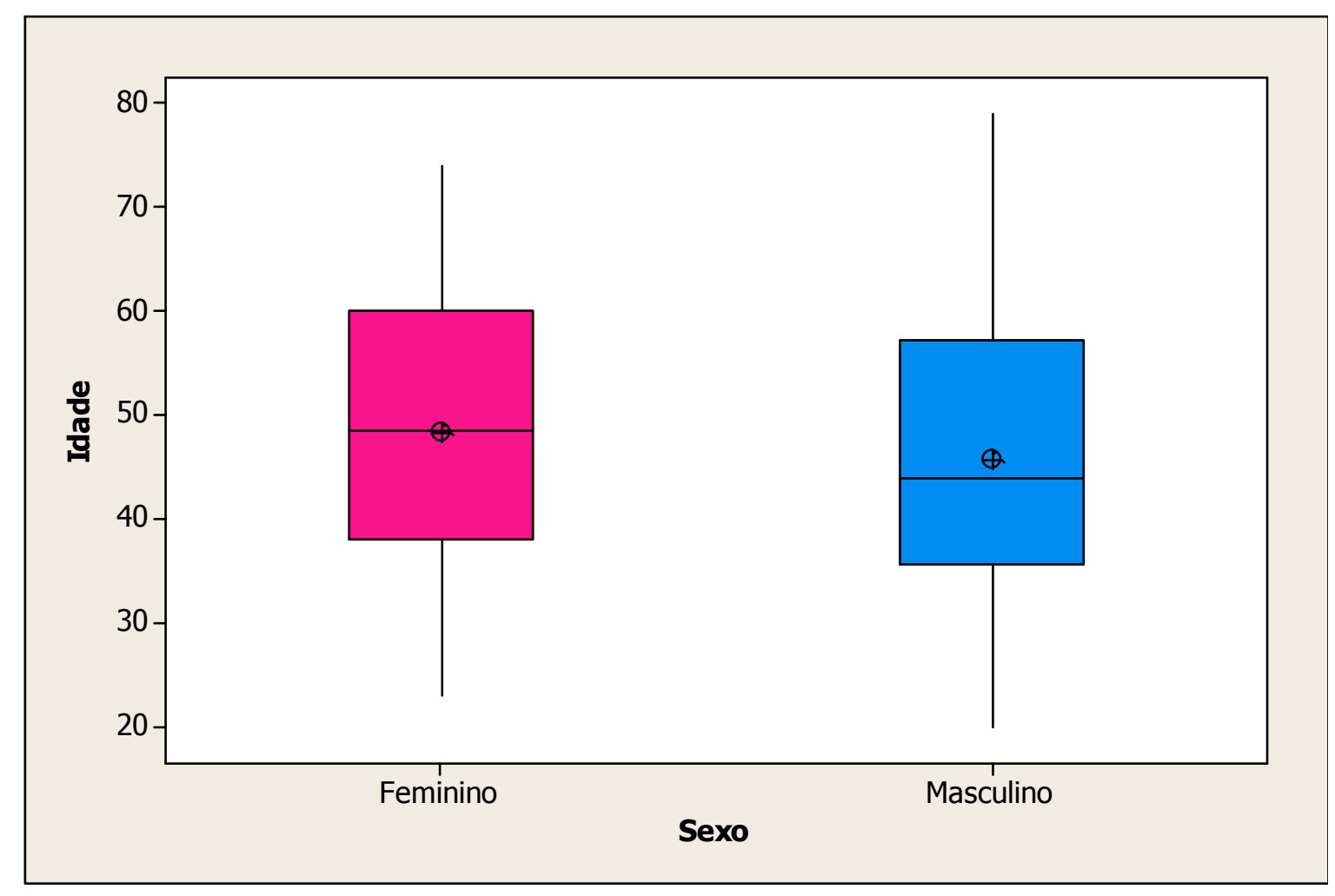

Figura 4- Box Plot - Idade dos familiares. São Paulo, 2011. 
A figura 5 apresenta a distribuição da escolaridade dos familiares. A maioria dos visitantes possui o Ensino Médio completo $\mathrm{N}=45$ (50\%).

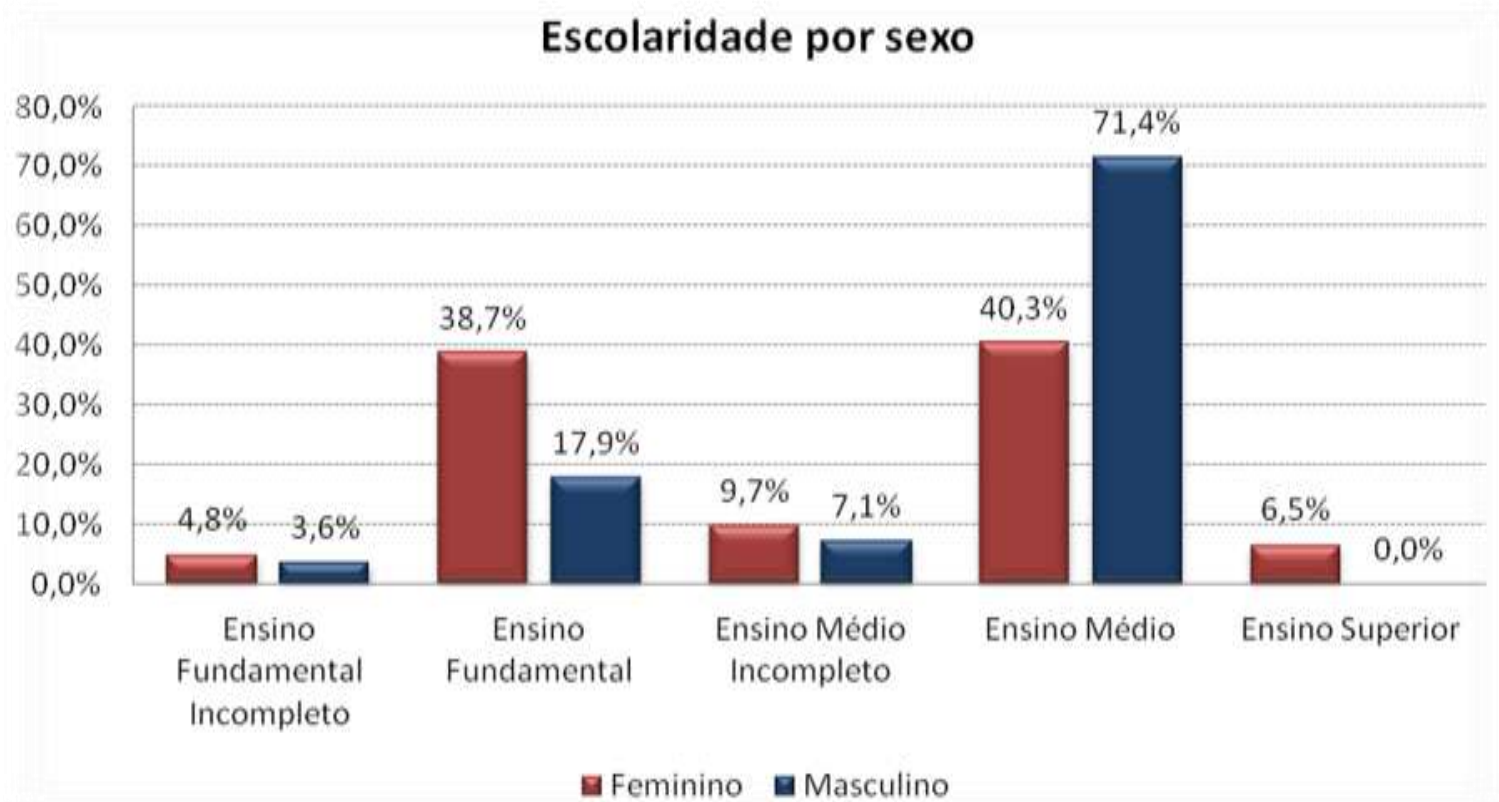

Figura 5- Distribuição da escolaridade dos familiares por sexo. São Paulo, 2011.

\subsection{CARACTERIZAÇÃO DAS VISITAS DE ENFERMAGEM}

$\mathrm{Na}$ análise das respostas obtidas nos formulários da Visita de Enfermagem observou-se que todos os familiares quiseram receber informações do enfermeiro nas três visitas realizadas com cada família.

A primeira visita de Enfermagem teve um tempo médio de 8,14 minutos com cada família. Neste primeiro momento, sessenta e sete familiares $(74,4 \%)$ quiseram saber sobre o estado clínico do paciente; cinco familiares $(5,5 \%)$ quiseram saber sobre resultados de exames; cinco familiares $(5,5 \%)$ tiveram dúvidas sobre as medicações que o paciente estava recebendo; quatro famílias (4,4\%) quiseram saber sobre 0 diagnóstico do paciente; quatro familiares $(4,4 \%)$ tiveram dúvidas sobre o 
equipamento "monitor"; e três familiares (3,3\%) quiseram saber sobre o prognóstico do paciente (Tabela 2).

Tabela 2- Número de famílias que apresentaram dúvidas sobre os temas no primeiro dia de Visita de Enfermagem. São Paulo - 2011

\begin{tabular}{ccc}
\hline Tema da dúvida & Número de Famílias & $\%$ \\
\hline Estado Clínico & 67 & $74,40 \%$ \\
Resultado de Exames & 5 & $5,50 \%$ \\
Medicação & 5 & $5,50 \%$ \\
Diagnósticos & 4 & $4,40 \%$ \\
Equipamentos da UTI & 4 & $4,40 \%$ \\
Prognóstico & 3 & $3,30 \%$ \\
\hline Total & 88 & $\mathbf{9 7 , 5 0 \%}$ \\
\hline
\end{tabular}

A tabela 3 mostra a frequência e os temas de citação do item "outros" do formulário (Apêndice I e II). 
Tabela 3- Número de famílias que apresentaram dúvidas sobre o item "outros" no primeiro dia de Visita de Enfermagem. São Paulo - 2011

\begin{tabular}{ccc}
\hline Tema & Número de famílias & $\%$ \\
\hline Sobre Alta & 10 & $11,10 \%$ \\
Presença de agitação & 4 & $4,40 \%$ \\
Sobre a cirurgia realizada & 4 & $4,40 \%$ \\
Porque veio para UTI & 3 & $3,30 \%$ \\
Se está dormindo & 2 & $2,20 \%$ \\
Se pode beber água & 2 & $2,20 \%$ \\
Presença de febre & 2 & $2,20 \%$ \\
Sobre Pressão Arterial & 2 & $2,20 \%$ \\
Sobre a cânula de intubação & 1 & $1,10 \%$ \\
Se está com dor & 1 & $1,10 \%$ \\
\hline Total & $\mathbf{3 1}$ & $\mathbf{3 4 , 4 \%}$ \\
\hline
\end{tabular}

A segunda visita de Enfermagem foi realizada com 84 famílias, pois 6 pacientes já haviam recebido alta da UTI e teve um tempo médio de 8,6 minutos com cada família. Neste segundo momento, sessenta e seis familiares $(78,6 \%)$ quiseram saber sobre o estado clínico do paciente; seis familiares $(7,1 \%)$ tiveram dúvidas sobre a medicação que o paciente estava recebendo; dois $(2,4 \%)$ quiseram saber sobre resultados de exames; um familiar $(1,2 \%)$ teve dúvida sobre o Prognóstico do paciente; nenhum familiar teve dúvidas sobre Diagnósticos e Equipamentos da UTI (Tabela 4).

Tabela 4- Número de famílias que apresentaram dúvidas sobre os temas no segundo dia de Visita de Enfermagem. São Paulo - 2011

\begin{tabular}{ccc}
\hline Tema da dúvida & Número de Famílias & $\%$ \\
\hline Estado Clínico & 66 & $78,6 \%$ \\
Medicação & 6 & $7,1 \%$ \\
Resultado de Exames & 2 & $2,4 \%$ \\
Prognóstico & 1 & $1,2 \%$ \\
Equipamentos da UTI & 0 & $0 \%$ \\
Diagnóstico & 0 & $0 \%$ \\
\hline Total & $\mathbf{7 5}$ & $\mathbf{8 9 , 3 \%}$ \\
\hline
\end{tabular}


A tabela 5 mostra a frequência e os temas de citação do item "outros" do formulário no segundo dia de Visita de Enfermagem (Apêndice I e II).

Tabela 5- Número de famílias que apresentaram dúvidas sobre o item "outros" no segundo dia de Visita de Enfermagem. São Paulo - 2011

\begin{tabular}{ccc}
\hline Tema da dúvida & Número de famílias & $\mathbf{\%}$ \\
\hline Sobre alta & 9 & $10,7 \%$ \\
Se está dormindo & 3 & $3,6 \%$ \\
Sobre a cânula de intubação & 2 & $2,4 \%$ \\
Sobre Pressão Arterial & 2 & $2,4 \%$ \\
Sobre exame que vai fazer & 1 & $1,2 \%$ \\
Se pode comer & 1 & $1,2 \%$ \\
Se pode beber água & 1 & $1,2 \%$ \\
Presença de febre & 1 & $1,2 \%$ \\
\hline Total & $\mathbf{2 0}$ & $\mathbf{2 3 , 8 \%}$ \\
\hline
\end{tabular}

A terceira visita de Enfermagem foi realizada com 62 famílias, pois 28 pacientes já haviam recebido alta da UTI e teve uma duração média de 8,6 minutos com cada família. Neste terceiro momento, quarenta e seis familiares $(74,2 \%)$ quiseram saber sobre o estado clínico do paciente; seis $(9,7 \%)$ quiseram saber sobre resultados de exames; dois familiares $(3,2 \%)$ tiveram dúvidas sobre diagnóstico; dois familiares $(3,2 \%)$ tiveram dúvidas sobre a medicação que o paciente estava recebendo; um familiar $(1,6 \%)$ teve dúvida sobre o Prognóstico do paciente; nenhum familiar teve dúvidas sobre Equipamentos da UTI (Tabela 6). 
Tabela 6- Número de famílias que apresentaram dúvidas sobre os temas no terceiro dia de Visita de Enfermagem. São Paulo - 2011

\begin{tabular}{ccc}
\hline Tema da dúvida & Número de Famílias & $\%$ \\
\hline Estado Clínico & 46 & $74,2 \%$ \\
Resultado de Exames & 6 & $9,7 \%$ \\
Diagnóstico & 2 & $3,2 \%$ \\
Medicação & 2 & $3,2 \%$ \\
Prognóstico & 1 & $1,6 \%$ \\
Equipamentos da UTI & 0 & $0 \%$ \\
\hline Total & $\mathbf{5 7}$ & $\mathbf{9 1 , 9 \%}$ \\
\hline
\end{tabular}

A tabela 7 mostra a frequência e os temas de citação do item "outros" do formulário no terceiro dia de Visita de Enfermagem (Apêndice I e II).

Tabela 7- Número de famílias que apresentaram dúvidas sobre o item "outros" no terceiro dia de Visita de Enfermagem. São Paulo - 2011

\begin{tabular}{ccc}
\hline Tema & Número de famílias & $\%$ \\
\hline Sobre alta & 11 & $17,7 \%$ \\
Presença de confusão mental & 2 & $3,2 \%$ \\
Sobre a cânula de intubação & 1 & $1,6 \%$ \\
Sobre pressão arterial & 1 & $1,6 \%$ \\
Se a infecção está controlada & 1 & $1,6 \%$ \\
Se vai operar novamente & 1 & $1,6 \%$ \\
\hline Total & $\mathbf{1 7}$ & $\mathbf{2 7 , 4 \%}$ \\
\hline
\end{tabular}

A tabela 8 apresenta a estatística descritiva do número de dúvidas para cada dia de visita. Foi realizado a ANOVA de medidas repetidas para verificar se existe diferença entre o número médio de dúvidas para os dias de visitas. Vemos que o número médio de dúvidas diminui ao passar das visitas $(p=0,000)$. 
Tabela 8- Número de dúvidas para cada dia de visita. São Paulo - 2011

\begin{tabular}{cccc}
\hline & Visita 1 & Visita 2 & Visita 3 \\
\hline Média \pm D.P. & $0.98 \pm 0.08$ & $0.83 \pm 0.06$ & $0.63 \pm 0.08$ \\
Mediana & 1 & 1 & 1 \\
Mínimo - Máximo & $0-3$ & $0-3$ & $0-3$ \\
\hline Total & 90 & 90 & 90 \\
\hline P valor $=\mathbf{0 . 0 0 0 0 *}$ & & & $*$ Estatisticamente significativo
\end{tabular}

Para efeito de comparação entre os dias de visita, foi realizado o teste t pareado. Os resultados são apresentados na tabela 9.

Tabela 9- Teste t pareado comparando as dúvidas entre os dias de visita. São Paulo - 2011

\begin{tabular}{cc}
\hline Faixa etária & P-valor \\
\hline Visita 1 x Visita 2 & 0.085 \\
Visita 1 x Visita 3 & $0.001^{*}$ \\
Visita 2 x Visita 3 & $0.031^{*}$ \\
\hline & * Estatisticamente significativo
\end{tabular}

A partir da tabela 9 pode-se tirar as seguintes conclusões:

- A diferença do número médio de dúvidas entre o primeiro dia e 0 segundo dia de visitas não é estatisticamente significativa $(p=0,085)$.

- O número médio de dúvidas do primeiro dia de visitas é estatisticamente maior comparado ao terceiro dia de visita $(p=$ 0,001). E o número médio de dúvidas do segundo dia de visitas é estatisticamente maior comparado ao terceiro dia de visitas $(p=$ 0.031). 
A Tabela 10 apresenta o número médio de dúvidas entre o sexo feminino e masculino, por dia de visita. A diferença do número médio de dúvidas entre o sexo feminino e masculino não é estatisticamente significativa para nenhum dos dias de visitas $(p=0,845, p=0,533$ e $p=$ 0,597).

Tabela 10- Número médio de dúvidas entre os sexos por dia de visita. São Paulo - 2011

\begin{tabular}{cccc}
\hline Visita & Sexo & Número médio de dúvidas & P valor \\
\hline \multirow{2}{*}{ Visita 1 } & Feminino & 0.968 & 0.845 \\
& Masculino & 1.000 & \\
\hline \multirow{2}{*}{ Visita 2 } & Feminino & 0.806 & 0.533 \\
& Masculino & 0.893 & \\
\hline \multirow{2}{*}{ Visita 3 } & Feminino & 0.661 & 0.597 \\
& Masculino & 0.571 & \\
\hline
\end{tabular}

\subsection{CARACTERIZAÇÃO DO QUESTIONÁRIO PÓS ALTA DO PACIENTE DA UTI}

$\mathrm{Na}$ análise das respostas obtidas nos questionários, com relação à primeira pergunta "Receberam as informações que gostariam de saber?", verificamos que noventa (100\%) responderam sim.

Como $100 \%$ dos participantes responderam sim para a primeira questão, a segunda questão que foi "Se não, quais faltaram?" não teve resposta. 
Na terceira questão "Ficou alguma dúvida em relação as informações que Ihes foram dadas?", noventa (100\%) dos entrevistados responderam que não.

$\mathrm{Na}$ quarta questão "O tempo de visita atendeu suas necessidades?" setenta e seis $(84,4 \%)$ dos entrevistados responderam que sim e quatorze $(15,6 \%)$ responderam que não. Os que responderam que não se justificaram dizendo que necessitavam de mais tempo de visita.

Na quinta questão "Como podemos melhorar o atendimento de vocês no horário de visita?", oitenta e cinco (94,4\%) dos entrevistados disseram estar Satisfeitos; três (3,3\%) responderam estar Muito Satisfeitos; um (1,1\%) respondeu que poderia ficar acompanhante; e um $(1,1 \%)$ disse que poderia haver rodízio de visita durante os horários. 


\section{DISCUSSÃO DOS RESULTADOS}

A comunicação da equipe de saúde com os familiares na UTI varia de pessoa para pessoa. Uma comunicação efetiva com esses familiares é a chave para tomadas de decisões corretas e preservação da autonomia do paciente; contudo, em um ambiente critico, muitas vezes, essa comunicação não é considerada como prioridade, o que pode ocasionar desentendimento e frustração nos familiares ${ }^{53-54-55}$.

Analisando os resultados obtidos caracterizamos os pacientes observados como sendo na sua maioria homens com uma faixa etária média de 57 anos, que permaneceram em média 5 dias internado na UTI por patologias clínicas. $E$, os familiares analisados eram na maioria do sexo feminino, com grau de parentesco "filha" seguido de "esposa", na faixa de 47 anos, dona de casa, com Ensino Médio completo.

O tempo médio de visita de enfermagem foi de 8 minutos nas três visitas realizadas com cada família, ou seja, parece ser possível obter um grau de satisfação da família mesmo com pouco tempo de contato entre o profissional e o familiar, pois o que importa não é o tempo gasto com o contato, mas sim a maneira como essa comunicação é realizada, como também citada em outros estudos ${ }^{37-38}$.

Todos os familiares quiseram receber informações do enfermeiro nas três visitas realizadas com cada família, o que demonstra que há necessidade de alguém da equipe de Enfermagem ser referência para os familiares; alguém a quem eles possam recorrer para uma conversa, esclarecendo suas dúvidas e sendo tranquilizados e orientados, como citado em outros estudos ${ }^{29,50}$. Muitos estudos sobre necessidades da família ${ }^{56-57}$ e satisfação com o cuidado ${ }^{58-59}$ tem demonstrado que uma boa habilidade de comunicação pela equipe da UTI, e flexibilidade na política de visitação na UTI podem ajudar os familiares nessa situação de dificuldade e incertezas ${ }^{56,60-61}$. 
Estudo realizado na UTI do Hospital do Câncer do Estado de São Paulo - Brasil sobre satisfação com a comunicação em UTI mostrou uma satisfação positiva associada a maior frequência de comunicação com a equipe multiprofissional, clareza sobre o diagnóstico e prognóstico, e bom relacionamento interpessoal $^{62}$.

Davidson et al $^{63}$ desenvolveram um manual prático de suporte a pacientes e familiares de UTI baseado em uma metanálise de 300 estudos. De acordo com o manual, a família quer frequente comunicação com a equipe de saúde e ser incluída nas discussões sobre as condutas a serem tomadas com o paciente. Também aprovam uma sala de espera onde possam ser dadas as informações pertinentes aos pacientes e maior flexibilidade no horário de visita.

Em análise qualitativa realizada com 880 familiares de pacientes de UTI, no Canadá, onde foram analisados 6 temas centrais de satisfação dos familiares: qualidade da equipe, qualidade do cuidado, comunicação, respeito com a paciente e familiar, sala de espera e leito do paciente, mostrou que as recomendações sugeridas foram estabelecer contatos regulares entre os membros da equipe e os familiares, principalmente quando os pacientes estão em estado mais crítico, melhorar as habilidades de comunicação e relacionamento interpessoal, incluir a família e o paciente nas tomadas de decisão e providenciar folhetos informativos sobre a $\mathrm{UTI}^{64}$. Neste estudo também ficou claro a importância do contato dos profissionais da UTI com os familiares para satisfação e atendimento de suas necessidades.

O tema de maior dúvida entre os familiares nas três Visitas de Enfermagem foi o Estado Clínico do paciente e, no item "outros" do formulário a maior dúvida por parte dos familiares foi sobre a Alta da UTI.

Ao fazermos a comparação das dúvidas levantadas nas três visitas de Enfermagem verificamos que o número médio de dúvidas diminui ao passar das visitas, sendo que o número médio de dúvidas do primeiro dia de visitas 
é estatisticamente maior comparado ao terceiro dia de visita $(p=0,001)$. E o número médio de dúvidas do segundo dia de visitas é estatisticamente maior comparado ao terceiro dia de visitas $(p=0.031)$. Também foi observado que a diferença do número médio de dúvidas entre o sexo feminino e masculino não é estatisticamente significativo para nenhum dos dias de visitas.

Esse resultado pode ser explicado devido ao fato de que, na maioria dos casos, a família está entrando na UTI e passando por esta situação de ter um de seus membros hospitalizados pela primeira vez, chegando com medo do estado do paciente e da "cena" que irão ver. Apresentam-se perdidos porque não conhecem os rituais desse setor e permanecem muito aflitos para falar com alguém da equipe, a fim de obter informação sobre 0 paciente, esclarecer dúvidas, assim como ter satisfeita sua necessidade de conforto, receber palavras carinhosas e de atenção ${ }^{34,45,49}$.

Estudo realizado com 205 famílias de pacientes de UTI na Inglaterra ${ }^{65}$ mostrou que a equipe de médicos e enfermeiros dessa UTI, quando praticam uma boa comunicação com a família, principalmente nos casos em que os pacientes estão em estado mais grave, o nível de satisfação dessas famílias aumenta diminuindo significantemente o estresse causado pela internação e gravidade da doença. Isso também foi observado em estudos que revelam que quando se tem uma comunicação efetiva com a família sobre o ruim prognóstico do paciente, eles aceitam com maior tranquilidade a condição clínica do seu ente querido e preferem que seja feita a "vontade de Deus", do que atos "heróicos" que prolonguem a vida e, consequentemente, o sofrimento do doente ${ }^{66-67}$.

$\mathrm{Na}$ análise do questionário, todos os familiares afirmam terem recebido as informações que gostariam de saber, não tendo ficado nenhuma dúvida em relação às informações que lhes foram transmitidas.

O tempo de visita foi satisfatório para a maioria dos familiares entrevistados, assim como o atendimento durante o horário de visita; porém, alguns familiares ainda sentem necessidade de um maior tempo de contato com o doente e uma flexibilidade de rodízio de visita para atender outras 
pessoas da família que gostariam de visitar e que não tem disponibilidade de vir nos horários pré-determinados.

Esses resultados sugerem que os aspectos importantes na comunicação com famílias nessa unidade de fornecer informações claras, concisas e com linguagem apropriada; permitir que os familiares perguntem e digam o que pensam e sentem, bem como, incentivá-los a falar sobre a situação que se encontram foram realizados, gerando uma comunicação adequada, com uma interação da família com a Enfermagem harmônica, manifestando um comportamento mais tranquilo, além de propiciar um cuidado humanizado, como já citado em outros estudos ${ }^{13,17,33-34-35-36,40-41}$.

Estudo piloto realizado em uma UTI na Suécia avaliou a satisfação dos familiares de acordo com as necessidades de garantia, informação, proximidade, suporte e conforto - todas incluídas no instrumento CCFSS (Critical Care Family Satisfaction Survey) traduzido inglês e validado para o sueco. Os resultados mostraram que houve necessidade de sinceridade por parte da equipe em relação a condição clínica dos pacientes. Houve satisfação da família pela clareza e periodicidade das informações dadas, pelos horários abertos para visitação, por participarem das práticas de intervenção e ficaram menos satisfeitos com o conforto da sala de espera ${ }^{68}$.

Outro estudo realizado em uma UTI da Noruega ${ }^{69}$ mostrou que a equipe da UTI necessita criar estratégias de comunicação para diminuir a ansiedade de família e torná-la mais participativa no processo de tomada de decisão sobre as condutas a serem tomadas com o paciente, principalmente se referindo a cuidados no fim da vida, ou seja, questões de participação da família nos cuidados se mantém presentes nos estudos encontrados, o que precisa, portanto ser valorizado quando se pretende aumentar o grau de satisfação dos familiares.

As Visitas de Enfermagem realizadas em três momentos consecutivos da internação do doente na UTI possibilitou mensurar e trabalhar a carga emocional e as principais dúvidas da família durante esse período, o que ajudou a detectar e prevenir precocemente sintomas de ansiedade, 
depressão e estresse vivenciados pelos familiares, assim como concluído em outros estudos ${ }^{48,70}$.

Atualmente, muitos estudos sobre comunicação estruturada com a família de pacientes de UTI têm sido feitos. Dentre eles, alguns mostram que intervenções para melhorar a comunicação e a tomada de decisão em unidades críticas tem incluído conversas pelo telefone de enfermeiras com familiares, consultas éticas e consulta sobre cuidado paliativo ativo ${ }^{20-21}$.

Uma revisão sistemática recente sobre intervenções de comunicação com familiares de UTI mostrou que as informações impressas em forma de folhetos ajudam os familiares a compreender mais sobre os cuidados e 0 ambiente UTI, assim como a comunicação regular e estruturada da equipe com a família auxilia na redução do estresse e na compreensão do tratamento feito na $\mathrm{UTI}^{22}$. Na UTI do estudo ainda não se transmite a informação por meio de folhetos, o que já vem sendo pensado como uma estratégia futura para complementar a comunicação estruturada através da visita de Enfermagem.

Recentemente, também, encontros formais programados com a família envolvendo visitas multidisciplinares afastadas do leito do paciente tem sido recomendadas para uma aproximação e um contato mais efetivo com a família, encorajando o diálogo sobre os objetivos do cuidado ${ }^{23-24}$. Apesar que neste estudo a visita de Enfermagem tenha sido realizada ao lado do leito, também se observou uma boa interação com os familiares possibilitando que os mesmos expusessem suas dúvidas.

Embora haja evidências de que aumentar a atenção às necessidades da família esteja associado a um aumento da satisfação e talvez redução do estresse do familiar, há pouca exploração sobre a influência da maneira como a comunicação com o familiar é realizada. Lautrette et $\mathrm{al}^{23}$ testaram o efeito de usar uma comunicação estruturada por meio de folhetos informativos sobre o processo de morrer com familiares de pacientes que iriam vivenciar a morte em poucos dias. Eles comprovaram uma diminuição 
dos sintomas de estresse pós traumático, ansiedade e depressão no grupo de intervenção.

Outro estudo realizado com 346 familiares de 5 UTIs dos EUA, que tinha como objetivo verificar se o uso de comunicação estruturada com a família de pacientes de UTI, com prognóstico ruim, diminuía sua longa permanência na unidade com cuidados que só prolongassem a vida, chegou a conclusão que não houve diminuição significativa do tempo de permanência ou de intervenções desnecessárias no grupo de intervenção. Porém, foi encontrada uma diminuição na ansiedade e das necessidades desses familiares ${ }^{25}$.

Um estudo semelhante que utilizou encontros multidisciplinares estruturados com a família para verificar se a comunicação e tomada de decisão no final da vida eram melhorados concluiu que houve uma melhora na comunicação e satisfação dos familiares ${ }^{26}$.

Comparando o resultado deste estudo com o resultado do estudo realizado por Marques, Silva e Maia $^{17}$, em 2009, no mesmo local, pode-se observar que naquele momento os familiares sentiam falta de um maior contato com a equipe, principalmente a de Enfermagem, pois viam nela uma maior aproximação e contato com o doente, o que foi suprimido neste estudo com a Visita de Enfermagem. Porém, em ambos, os familiares reafirmam a necessidade de um maior tempo de contato com o ente querido, visto que de 2009 para 2011 não houve aumento no tempo de visita na UTI dos estudos, o que poderá ser uma proposta de intervenção futura.

Os estudos citados e o atual reafirmam que os enfermeiros tem um papel fundamental na comunicação com as famílias, inclusive intervindo na comunicação entre médicos e familiares, pois esses se sentem mais seguros em solicitar alguma informação que não tenha ficado clara no momento da conversa com o médico.

A equipe da UTI necessita, diante desses resultados, estar preparada para lidar com o estresse das famílias e fornecer apoio emocional e 
informações sobre os pacientes, o que faz com que os familiares possam auxiliar no cuidado e na tomada de decisões sobre o paciente ${ }^{71-72-73}$.

Estudos recentes mostram algumas alternativas para lidar com a carga emocional dos enfermeiros de UTI e auxiliá-los a dar um melhor suporte para a família. Loiselle et $\mathrm{al}^{74}$ utilizaram o programa ASP (Adler/Sheiner Programme) ${ }^{75}$, desenvolvido no Canadá, que tem como objetivo assistir pacientes e familiares de UTI para ajudá-los a compreender melhor essa unidade crítica e providenciar informação, suporte emocional e pesquisas sobre comunicação para enfermeiros. Os resultados desse estudo mostram que houve um aumento na satisfação e melhora dos sintomas físicos e mentais de estresse dos enfermeiros o que, consequentemente, melhorou a comunicação com os familiares e pacientes.

Estratégias como esta poderiam ser desenvolvidas e aplicadas com os Enfermeiros, na UTI do estudo, visto que esses também sentem dificuldades em transmitir uma comunicação efetiva com a família devido à falta de preparo e valorização da interação com o familiar, assim como citado no estudo de Marques, Silva e Maia ${ }^{18}$. 


\section{CONCLUSÕES E CONSIDERAÇÕES FINAIS}

Com os resultados desse estudo, concluímos que a implementação da Visita de Enfermagem na Unidade de Terapia Intensiva do Hospital Universitário da Universidade de São Paulo atingiu seu objetivo que foi atender as principais necessidades de informação e acolhimento dos familiares durante o horário de visita, respondendo suas questões sobre o cuidado de Enfermagem prestado para o paciente. Também foi observado que com a visita diária de Enfermagem as dúvidas e ansiedades dos familiares diminuíram no decorrer dos dias, enfatizando a necessidade desse contato entre Enfermeiros e Familiares.

A validação da Visita de Enfermagem foi feita aplicando o questionário de satisfação da família no pós alta do paciente da UTI, onde a satisfação do atendimento foi observada em todas as respostas do questionário.

Quando comparado o resultado desse estudo com o estudo preliminar realizado no mesmo local, observou-se melhora da satisfação da família com o atendimento de Enfermagem durante o horário de visita, tendo a Visita de Enfermagem como intervenção entre os dois estudos.

Tendo comprovado a importância da Visita de Enfermagem no ambiente da UTI, considera-se importante trabalhar com a equipe de Enfermagem estratégias de comunicação para que todos consigam atender as necessidades dos familiares durante a visita, visto que alguns Enfermeiros ainda sentem dificuldade nesta interação. 


\section{LIMITAÇÕES DO ESTUDO}

Este estudo apresentou algumas limitações; a coleta de dados foi feita em apenas uma UTI o que torna difícil generalizar os resultados; diferentes subgrupos de participantes como, por exemplo, por suas idades, grau de parentesco e escolaridade foi pequeno para uma análise estatística. Também foi difícil comparar os resultados desse estudo com outros estudos nacionais, para uma melhor aproximação da população, pois faltam publicações recentes abordando a temática de comunicação estruturada. Porém, a idéia da implantação da Visita de Enfermagem na UTI do estudo foi acatada pela diretoria da instituição e está sendo realizada nos três horários de visita dessa UTI pelos enfermeiros da unidade. Posteriormente podem-se fazer novos estudos sobre como a realização dessa visita está sendo feita e realizar novas avaliações para aperfeiçoamento da mesma. 


\section{Referências ${ }^{1}$}

1. Nascimento ERP, Trentini M. O cuidado de enfermagem na unidade de terapia intensiva: teoria humanística de Paterson e Zderad. Rev Lat Am Enferm 2004; 12(2):250-7.

2. Guirardello EB, Romero-Gabriel CAA, Pereira IC, Miranda AF. A percepção do paciente sobre sua permanência na UTI. Rev. Esc. Enf. USP 1999; 33(2): 123-9.

3. Fortes PAC, Martins CL. A ética, a humanização e a saúde da família. Rev Bras Enferm 2000;53(n.esp):31-3.

4. Stefanelli MC, Carvalho EC. A comunicação nos diferentes contextos da Enfermagem. Barueri: Manole; 2005.

5. Silva RF, Carvalho EC. A comunicação administrativa escrita na enfermagem. Rev. Paul. Enf. 1993; 12(1): 43-8.

6. Stefanelli MC. Comunicação com o paciente: teoria e ensino. São Paulo (SP): Robe; 1993.

7. Silva MJP. Comunicação tem remédio: a comunicação nas relações interpessoais em saúde. São Paulo (SP): Loyola; 2008.

8. Sitzer VA. Enhancing communication with critically ill patients and families. In: Clochesy JM, Breu C, Cardin S, Whittaker AA, Rudy EB. Crit. Care Nur. Philadelphia: W.B. Saunders; 1996.cap.7,p.74-82.

9. Marcon SS., Lopes MC, Antunes CRM, Fernandes J, Waidman MAP. Famílias cuidadoras de pessoas com dependência: um estudo bibliográfico. Online Brazilian Journal of Nursing [periódico na internet]. 2006; 5(1). Disponível em:www.uff.br/ objnursing.

10. Oliveira OS, Nóbrega MML, Silva ATMC, Filha MOF. Comunicação terapêutica em enfermagem revelada nos depoimentos de pacientes 
internados em centro de terapia intensiva. Rev Eletron Enferm [periódico na internet]. 2005; 7(1):54-63.

11. Nascimento AZ, Ribeiro G, Bernardino E, Oliveira ES. Limites e possibilidades da permanência de familiares em Unidade de terapia intensiva. Cogitare Enferm. 2007 Out/Dez;12 (4):446-51.

12. Cintra EA, Nishide VM, Nunes WA. Assistência de enfermagem ao paciente gravemente enfermo. $2^{\underline{a}}$ ed. São Paulo: Atheneu; 2003.

13. Ribeiro JA, Santos MSS. Diagnóstico de necessidades da família de clientes adultos na unidade de terapia intensiva: revisão de literatura. Cogitare Enferm. 2008 Jul/Set; 13(3):437-42.

14. Molter N. Needs of critically ill patients: a descriptive study. Heart \& Lung 1979 March-April; 3(2):332-9.

15. Castro DS. Estresse e estressores dos familiares de pacientes com traumatismo crânio - encefálico em terapia intensiva. [tese]. Rio de Janeiro (RJ): Escola de Enfermagem Anna Nery/UFRJ; 1999.

16. Morgon FH, Guirardello EB. Validação da escala de razão das necessidades de familiares em Unidade de Terapia Intensiva. Rev Latam Enferm 2004 março-abril; 12(2):198-203.

17. Marques RC, Silva MJP, Maia FOM. Comunicação entre profissionais de saúde e família de pacientes internados na UTI. Rev. enferm. UERJ, Rio de Janeiro, 2009 jan/mar; 17(1):91-5.

18. Marques RC, Silva MJP, Maia FOM. Comunicação efetiva com família de pacientes em cuidados críticos: percepção dos profissionais de saúde. Rev. Enferm. Herediana. 2008; 1(2): 63-68.

19. Aguilar MJ, Ander-Egg E. Avaliação de serviços e programas sociais. Petrópolis (RJ): Vozes; 1994.

20. Medland JJ, Ferrans CE. Effectiveness of a structured communication program for family members of patients in an ICU. Am J Crit Care 1998; $7(1): 24-29$.

${ }^{1}$ De acordo com o Estilo Vancouver 
21. Campbell ML, Guzman JA. Impact of a proactive approach to improve end-of-life care in a medical ICU. Chest 2003;123(1):266 - 271.

22. Scheunemann LP, McDevitt M, Carson SS, Hanson LC. Randomized, controlled trials of interventions to improve communication in intensive care: a systematic review. CHEST 2011; 139(3):543-554.

23. Lautrette $A$, Darmon $M$, Megarbane $B$, et al . A communication strategy and brochure for relatives of patients dying in the ICU. $N$ Engl $J$ Med 2007;356(5): 469 - 478.

24. Gay EB, Pronovost PJ, Bassett RD, Nelson JE. The intensive care unit family meeting: making it happen. J Crit Care 2009;24(4):629, e1-e12.

25.Daly BJ, Douglas SL, O'Toole E, Gordon NH, Hejal R, Peerless J, Rowbottom J, Garland A, Lilly C, Wiencek C, Hickman R. Effectiveness trial of an intensive communication structure for families of long-stay ICU patients. CHEST 2010; 138(6):1340-1348.

26. Jacobowski NL, Girard TD, Mulder JA, Ely EW. Communication in critical care: family rounds in the intensive care unit. American Journal of Critical Care. 2010;19:421-430.

27. Bruschine C. Uma abordagem sociológica de família. Rev. Bras. Est. Pop. São Paulo 1989; 6(1): 1-23.

28. Silva de Souza SRO, Chaves SRF, Silva CA. Visita na UTI: um encontro entre desconhecidos. Rev Bras Enferm 2006 set-out; 59(5): 609-13.

29. Soares M. Cuidando da Família de Pacientes em Situação de Terminalidade Internados na Unidade de Terapia Intensiva. Rev. Bras. de Ter Intens 2007; 19( 4):481-84.

30. Wright LM, Leahey M. Enfermeiras e famílias: um guia para avaliação e intervenção na família. 4aㅡ Ed. São Paulo: Roca; 2009. 
31. Allmond BW, Buckman W, Gofman HF. The Family Is the Patient: An Approach to Behavioral Pediatrics for the Clinician. St Louis, Missouri: C. V. Mosby; 1979, 387pp.

32. Angelo $M$. Com a família em tempos difíceis: uma perspectiva de enfermagem. [tese]. São Paulo (SP): Escola de Enfermagem da USP; 1997.

33. Pinheiro EM, Balbino FS, Balieiro MMFG, De Domenico EBL, Avena MJ. Percepções da família do recém-nascido hospitalizado sobre a comunicação de más notícias. Rev Gaúcha Enferm., Porto Alegre (RS) 2009 mar;30(1):77-84.

34. Gotardo GIB, Silva CA. O cuidado dos familiares na UTI. Rev. Enferm UERJ 2005; 13:223-8.

35. Moritz RD. Como Melhorar a Comunicação e Prevenir Conflitos nas Situações de Terminalidade na Unidade de Terapia Intensiva. Rev. Bras. de Ter. Intens. 2007; 19(4):485-89.

36. Cabrera LS, Rodriguez AR, Martul MG, Palacios MS, Gonzalez JCM, Medina EH. Encuesta de satisfaccióna los familiares de pacientes críticos. Madrid. Med. Intensiva 2007; 31(2).

37. Fassier T, Darmon M, Laplace C, Chevret S, Schlemmer B, Pochard F, Azoulay E. One-day quantitative cross-sectional study of family information time in 90 intensive care units in France. Crit Care Med 2007; 35(1): 177-83.

38. Stapleton RD, Engelberg RA, Wenrich MD, Goss CH, Curtis JR. Clinician statements and family satisfaction with family conferences in the intensive care unit. Crit Care Med 2006; 34 (6): 1679-85.

39. Lautrette A, Ciroldi M, Ksibi H, Azoulay E. End-of-life family conferences: Rooted in the evidence. Crit Care Med 2006; 34(11supl): 364-72. 
40. Boyle DK, Miller PA, Forbes-Thompson SA. Communication and End-ofLife Care in the Intensive Care Unit: Patient, Family, and Clinician Outcomes. Crit Care Nurs Q 2005; 28 (4): 302-16.

41. Levin TT, Moreno B, Silvester W, Kissane DW. End-of-life communication in the intensive care unit. General Hospital Psychiatry 2010; 32: 433-442.

42. Santos KMAB, Silva MJP. Percepção dos profissionais de saúde sobre a comunicação com familiares de pacientes de UTIs. Rev Bras Enferm 2006 jan-fev; 59(1): 61-6.

43. Nieweglowski VH, Moré CLOO. Comunicação equipe-família em unidade de terapia intensiva pediátrica: impacto no processo de hospitalização. Estudos de Psicologia Campinas 2008; 25(1): 111-122.

44. Maciel MR, Souza MF. Acompanhante de adulto na Unidade de Terapia Intensiva: uma visão do paciente. Acta Paul Enferm 2006; 19(2): 138-43.

45. Inaba LC, Silva MJP, Telles SCR. Paciente crítico e comunicação: visão de familiares sobre sua adequação pela equipe de enfermagem. Rev Esc Enferm USP 2005; 39(4):423-9.

46. Williams CM. The identification of family members' contribution to patients' care in the intensive care unit: a naturalistic inquiry. Nurs. in Crit. Care 2005; 10( 1$)$ : 6-14.

47. Shelton W, Moore CD, Socaris S, Gao J, Dowling J. The effect of a family support intervention on family satisfaction, length-of-stay, and cost of care in the intensive care unit. Crit Care Med 2010; 38:1315-1320.

48. Kentish-Barnes N, Lemiale V, Chaize M, Pochard F, Azoulay E. Assessing burden in families of critical care patients. Crit Care Med 2009; 37 (10 Suppl):448-56.

49. Victor ACS, Matsuda LM, Saalfeld SMS, Évora YDM. Comunicação verbal de uma equipe médica: percepções e necessidades de visitantes de uma UTI. Acta Scientiarum. Health Sciences. Maringá 2003; 25(2): 199-206. 
50. Wallau RA, Guimarães HP, Falcão LFR, Lopes RD, Leal PHR, Senna APR, Alheira RG, Machado FR, Amaral JLG. Qualidade e humanização do atendimento em medicina intensiva. Qual a visão dos Familiares. Rev. Bras. de ter. Intens. 2006; 18(1): 45-51.

51. Costa RCF, Costa JLF, Gutierrez FLBR, Mesquita AFM. Como implementar cuidados paliativos de qualidade na Unidade de Terapia Intensiva. Rev. Bras. de ter. Intens. 2008; 20(1): 88-92.

52. Polit DF, Beck CT, Hungler BP, editors. Fundamentos de Pesquisa em Enfermagem. 5a ed. São Paulo: Artmed; 2004.

53. Azoulay E, Sprung CL: Family-physician interactions in the intensive care unit. Crit Care Med 2004, 32(11):2323-8.

54. Fox S, Jeffrey J: The role of the nurse with families of patients in ICU: the nurses' perspective. Can J Cardiovasc Nurs 1997, 8(1):17-23.

55. LeClaire MM, Oakes JM, Weinert CR: Communication of prognostic information for critically ill patients. Chest 2005, 128(3):1728-35.

56. Alvarez GF, Kirby AS. The perspective of families of the critically ill patient: their needs. Curr Opin Crit Care 2006; 12:614-8.

57. Paul F, Rattray J. Short-and long-term impact of critical illness on relatives:literature review. J Adv Nurs 2008; 62:276-92.

58.Damghi N, Khoudri I, Oualili L, Abidi K, Madani N, Zeggwagh AA, et al. Measuring the satisfaction of intensive care unit patient families in Marocco: a regression tree analysis. Crit Care Med 2008;36:2084-91.

59. Stricker KH, Kimberger O, Schmidlin K, Zwahlen M, Mohr U, Rothen HU. Family satisfaction in the intensive care unit: what makes the difference? Intensive Care Med 2009;35:2051-9.

60. McDonagh JR, Elliott TB, Engelberg RA, Treece PD, Shannon SE, Rubenfeld GD, et al. Family satisfaction with family conferences about end-of-life care in the intensive care unit: increased proportion of family

${ }^{1}$ De acordo com o Estilo Vancouver 
speech is associated with increased satisfaction. Crit Care Med 2004;32:1484-8.

61. Heyland DK, Rocker GM, Dodek PM, Kutsogiannis DJ, Konopad E, Cook DJ, etal. Family satisfaction with care in the intensive care unit: results of a multiple center study. Crit Care Med 2002;30:1413-8.

62. Fumis $R$, Nishimoto I, Deheinzelin D: Families' interactions with physicians in the intensive care unit: the impact on family's satisfaction. $J$ Crit Care 2008; 23:281-286.

63. Davidson JE, Powers K, Hedayat KM, et al: Clinical practice guidelines for support of the family in the patient-centered intensive care unit: American College of Critical Care Medicine Task Force 2004-2005. Crit Care Med 2007; 35:605-622.

64. Henrich NJ, Dodek P, Heyland D, Cook D, Rocker G, Kutsogiannis D, Dale C, Fowler R, Ayas N. Qualitative analysis of an intensive care unit family satisfaction survey. Crit Care Med 2011; 39:1000-1005.

65. Siddiqui S, Sheikh F, Kamal R. "What families want - an assessment of family expectations in the ICU".Int Arch Med 2011;4:21.

66. Nierman DM, Schechter CB, Cannon LM, Meier DE. Outcome prediction model for very elderly critically ill patients. Crit Care Med 2001, 29(10):1853-9.

67. Sibbald R, Downar J, Hawryluck L. Perceptions of "futile care" among caregivers in intensive care units. Cmaj 2007, 177(10):1201-8.

68. Karlsson C, Tisell A, Engström A, Andershed B. Family members' satisfaction with critical care: a pilot study. Nurs Crit Care 2011;16(1):118.

69. Lind R, Lorem GF, Nortvedt P, Hevrøy O. Family members' experiences of "wait and see" as a communication strategy in end-of-life decisions. Intensive Care Med 2011; 37:1143-1150. 
70. Myhren $\mathrm{H}$, Ekeberg $\varnothing$, Stokland $O$. Satisfaction with communication in ICU patients and relatives: comparisons with medical staffs' expectations and the relationship with psychological distress. Patient Educ Couns $2011 ; 85(2): 237-44$.

71. Plakas S, Cant B, Taket A. The experiences of families of critically ill patients in Greece: a social constructionist grounded theory study. Intensive and Critical Care Nursing 2009; 25:10-20.

72. Fridh I, Forsberg A, Bergbom I. Close relatives' experiences of caring and of the physical environment when a loved one dies in an ICU. Intensive and Critical Care Nursing 2009; 25: 111-119.

73.S"oderstr"om IMK, Saveman BI, Hagberg MS, Benzein E. Family adaptation in relation to a family member's stay in ICU. Intensive and Critical Care Nursing 2009; 25: 250-257.

74. Loiselle CG, Gélinas C, Cassoff J, Boileau J, McVey L. A pre-post evaluation of the Adler/Sheiner Programme (ASP): A nursing informational programme to support families and nurses in an intensive care unit (ICU). Intensive and Critical Care Nursing 2012;28:32-40.

75. Loiselle CG, Dubois S. Getting wired for interactive health communication. Can Nurse 2003;99:22-6. 


\section{Apêndices}

\section{Apêndice I}

Formulário da primeira visita após a internação do paciente

Dia:

Hora:

Tempo da visita de enfermagem:

Nome do Entrevistador:

Paciente/Leito: Data de Admissão:

Diagnóstico:

Nome do familiar e grau de parentesco:

O familiar quis receber informações do enfermeiro? ( ) Sim （ ) Não

Se sim, sobre quais assuntos:

( ) Diagnóstico do paciente

( ) Prognóstico do paciente

( ) Equipamentos da UTI, Quais?

( ) Medicação que o paciente está recebendo

( ) Resultado de exames

( ) Estado clínico

( ) Outros. Quais?

Para os familiares, as respostas dadas foram inicialmente suficientes? ( ) $\operatorname{Sim}$ ( ) Não

Se não, quais assuntos gostariam de receber mais informações ou ficaram com dúvidas? 
Apêndice II

\section{Formulário de acompanhamento de visita}

Dia:

Hora:

Tempo da visita de enfermagem:

Nome do Entrevistador:

Paciente/Leito: Dia de internação:

Presença de familiar: ( ) Sim ( ) Não

Nome do familiar e grau de parentesco:

É a primeira visita deste familiar na UTI: ( ) Sim ( ) Não

O familiar quis receber informações do enfermeiro? ( ) Sim （ ) Não

Se sim, sobre quais assuntos:

( ) Diagnóstico do paciente

( ) Prognóstico do paciente

( ) Equipamentos da UTI. Quais?

( ) Medicação que o paciente está recebendo

( ) Resultado de exames

( ) Estado clínico

( ) Outros. Quais?

Para os familiares, as respostas dadas foram suficientes? ( ) Sim （ ) Não

Se não, quais assuntos gostariam de receber mais informações ou ficaram com dúvidas? 
Apêndice III

Dados de identificação do participante

Idade:

Sexo:

Profissão:

Grau de escolaridade:

Parentesco:

Quantos dias seu familiar ficou na UTI?:

Quantas visitas fez a este familiar enquanto ele esteve na UTI?

\section{Questões}

1. Receberam as informações que gostariam de saber? [ ]sim [ ] não

2. Se não, quais faltaram?

3. Ficou alguma dúvida em relação as informações que Ihes foram dadas? [ ]sim [ ]não, Qual?

4. O tempo da visita atendeu suas necessidades? [ ]sim [ ]não Por quê?

5. Como podemos melhorar o atendimento de vocês no horário de visitas? 


\section{Anexo}

\section{Termo de Consentimento Livre e Esclarecido}

Prezado Colaborador,

Estou desenvolvendo minha dissertação de mestrado intitulada Avaliação da Implantação da visita de Enfermagem com Familiares de pacientes de uma Unidade de Terapia Intensiva Adulto, sob orientação da Prof ${ }^{\mathrm{a}}$ Dr $^{\mathrm{a}}$ Maria Júlia Paes da Silva, da EEUSP.

O objetivo deste estudo é implementar a visita de enfermagem na UTI do Hospital Universitário da USP e após avaliar se as necessidades dos familiares foram suprimidas.

Para a validação teórica deste estudo necessito de sua valorosa contribuição respondendo as perguntas realizadas durante a Visita de Enfermagem, enquanto seu familiar esteve na UTI, e após a alta de seu familiar da UTI, responder a uma entrevista na qual será questionada a caracterização do respondente e 5 questões sobre suas dúvidas enquanto seu familiar esteve internado na UTI.

Você tem total liberdade em responder ou não às questões e em querer ou não que as informações coletadas durante a Visita de Enfermagem seja utilizadas.

Informo que você não terá despesas e nem prejuízo; que seu familiar não será lesado em qualquer tratamento que faça no $\mathrm{HU}$ e que seu nome ou do seu familiar não será citado no trabalho. Caso não queria participar do estudo, os dados coletados anteriormente, durante a visita de enfermagem na UTI, serão desprezados. 
Qualquer dúvida, meu nome é Rosemary Cristina Marques Simoni e você pode entrar em contato comigo pelo telefone (11)95847491 ou pelo email: rosecmarques @yahoo.com.br, ou pelo Comitê de Ética em Pesquisa da EEUSP pelo e-mail: edipesa@usp.br.

Esse Termo de Consentimento será elaborado em 2 (duas) vias e uma delas ficará com você e outra comigo.

Sim, aceito responder a entrevista desta pesquisa.

( nome legível e por extenso)

(assinatura)

Documento de identificação:

(escreva tipo

e número) 